\title{
Introduction to: The Value of Living Systems Beyond a Price
}

\author{
Jelena Sučić ${ }^{1,2^{*}}$, Susu H. Nousala ${ }^{2,3,4}$, Pier Paolo Peruccioo ${ }^{1}$ \\ ${ }^{1}$ DAD-Department of Architecture and Design, Politecnico di Torino, Torino, Italy \\ ${ }^{2}$ D\&I-College of Design \& Innovation, Tongji University, Shanghai, China \\ ${ }^{3}$ Department of Industrial Design, Wuhan University of Technology, Wuhan, China \\ ${ }^{4}$ Department of Architecture, Building and Construction, University of Melbourne, Melbourne, \\ Australia
}

\section{Email Address}

s.jelena@me.com (Jelena Sučić)

*Correspondence: s.jelena@me.com

Received: 26 March 2019; Accepted: 20 April 2019; Published: 5 May 2019

\begin{abstract}
:
Nowadays, the main topic on everybody's lips, corporations' and governments' heads but also common citizens', is "sustainability". This term is often abused to capture attention but it can be understood only by defining the contextual structure of what is intended to be done for achieving a sustainable state or process.

Core problems: human life and nature life distancing, which is creating a generational gap, proven by the population growth and movement towards cities. Our youth have never learnt to be in relation with life and other living systems, because they are already the result of being at least 3rd generation of a family that has moved from the countryside to the city. Who is going to transmit the knowledge, experiences and culture to the future population? How?

Losing the perception of value of our basic needs what come strictly out of nature, in particularly plants, which are the primary producers in the world and our primary source of food. If we lose the knowledge and experience of obtaining things naturally, and the recognizance of this principle on wide scale and every age for generations we will not be able to sustain us from our natural resources, so our sustainment will remain unsustainable in relation with the entire living biosphere.

Plants are organism that pre date human, are highly adaptive and reactive as we humans are. The only difference being is that we cannot provide for ourselves without them. Even if we think on technological solutions, we need a natural source for any synthesizing process we may plan to consider as solution, for example in terms of food: 'Cultured Meat' [1].

Out of these, is emerging that all our solutions are actually already in nature and plants because of their high reactivity and relation in living systems are the most sustainable technologies to solve our problems.

The process and the approach shown in the following paper and case study scenario are explained through multidisciplinary, transdisciplinary, multicultural and multigenerational contributions, that are necessary for fundamental ways for shaping long-term relations between citizens and plants. This approach opens new dynamic potentials for re-establishing viewpoints when considering plants as living processes as sustainable technologies. This thinking is applicable at any scale and context, and will require new approaches to learning, creating in turn, new educational paradigms.
\end{abstract}




\section{Keywords:}

Sustainability, Sustainable Technologies, Plants, Citizens, Generational Knowledge, Educational Production, Life Processes, Natural Systems, Permaculture

\section{Introduction: Development Process}

As a research oriented in design field, it has to be declared that the content examined in the following pages wants to understand the global environmental problems we are facing and the understanding tendency of them at common citizens level, meaning common people living in cities. The aim is, by finding case scenarios in common daily life, define an integrative project action to design which effects if spread as behaviours can contribute to alleviate global impacts.

Sustainability, a term which meaning cannot be understood without defining the context, has been explained in several ways, especially combined with the word 'development'.

Development is often associated to Growth which is considered quantitative. On the other hand, if we view development from the qualitative position it can become difficult to position with regards to positive or negative constrains. By upgrading the perspective of the word, development actually means a movement of constant changes which includes beginnings and ends. [2]

Sustainable development's definitions that might be find are general, social, economic, economic integrated with environment and ecological. Current key concepts to keep in mind are Equity and Limits to Growth. These limits are not predefined by our society but by the biosphere's ability to absorb or react on the effect of the preponderant human living activities. According to the response of the biosphere, the limits of human adaptability are and will be tested in social and political organizations' and technology appliances. [3] These feedback loop shows already the effects of the Equity concept, where every living system has its relevance in the entire biosphere and we all need to keep responding and adapting to find and equilibrium flow. For achieving this we need to focus efforts on the basic needs of life first. As Buckminster and Boulding have already stated: "We are all active on the same Spaceship Earth" [4] and we have to learn and adapt how to live all together in harmony.

Other very frequent emergent terms of our global issues are Climate Change and Air Pollution, widely recognized by common citizens but also Extreme Weather Changes, heat waves, floods and droughts which affect a lot our food provisions, living infrastructures, health and ecosystems reactions.

Leading institutions as UN, Club of Rome, Stockholm Resilience Centre, mention of course economic problems, which derivate all from a lack of consideration of basic priorities as life preservation; soil exploitation/erosion, which is a consequence of our choice of modeling production and consumption; and Biosphere integrity. This refers to the Biodiversity loss, which is another crucial issue, if not the main under the attention of the institutions right now. As Cristiana Pasca Palmer explains clearly [5] and the Stockholm Resilience Centre enhances even more in numerical data with the Nine Boundaries identified by the Planetary Boundaries Research which may be managed by following the UN 17 Global Goals for Sustainable Development [6] [7]. 


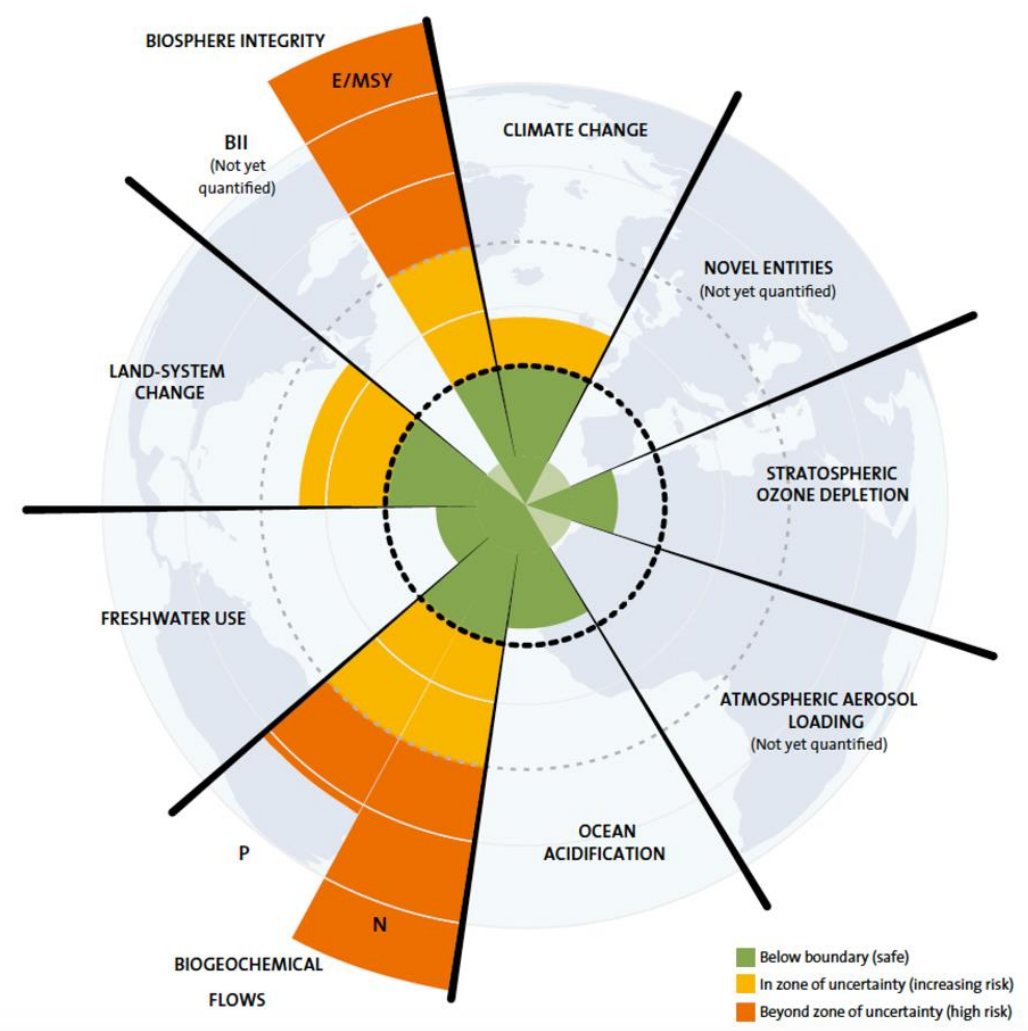

Figure 1. Nine planetary boundaries (PB) from Rockström et al. (2009) and Steffen et al. (2015). The dotted area represents the safe operating space. The greater the human-caused perturbation, the greater the risk of large-scale abrupt, and irreversible Earth system changes. [6]

\section{THEGLOBALGOALS \\ For Sustainable Development}
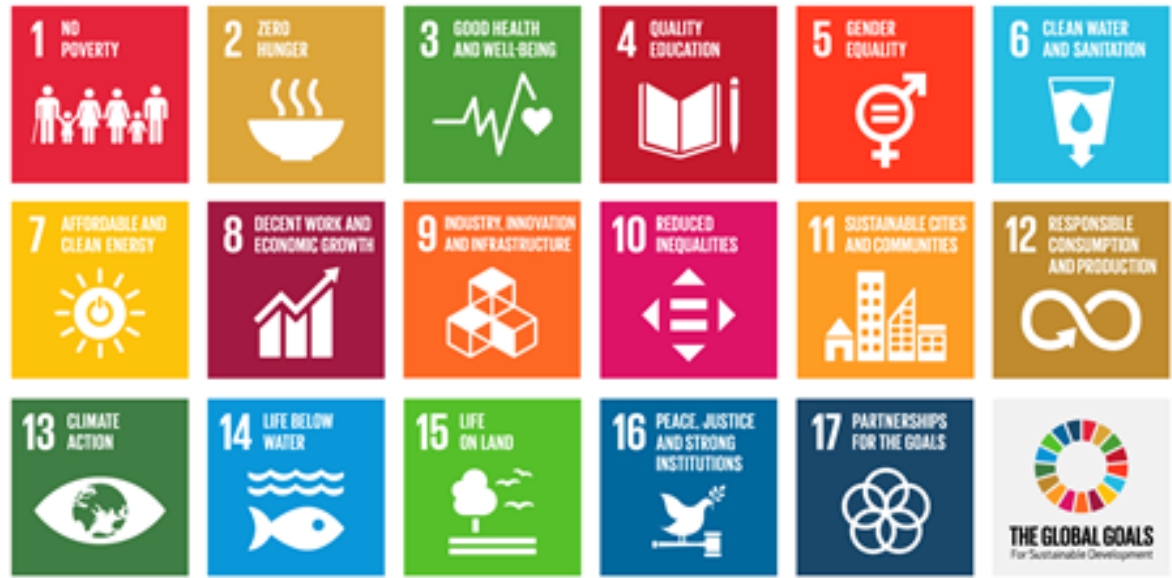

Figure 2. The 17 UN Global Goals for Sustainable Development [7].

The goal is in finding doorways or transition occasions to activate sustainable behaviors and choice changes process in single common citizens, then groups, and maintain them active, progressive and available to future generations.

Thanks to experience understanding processes, identify potential natural resources and natural technologies to react positively towards our global issues. 


\section{General Problem of Environmental Systems Perception}

The general problem of urban humans' system perception which is concentrate on economic, social and cultural systems, is that are emerging environmental signs and changes that cannot be positioned in any of these three systems. We have learned to value our life in relation with products and measure it by number of possessions and kind of selections we do. These define our level of life inside our economic, social and cultural systems. [8] Until recent times, we have never considerate the effects of our products, possessions, selections. We have never stopped to consider these relationships between our behavioral choices and environmental phenomena.

Environment meaning the totality of surrounding conditions [9], which means that everything we initiate in our three systems is going to be activated in the environment. Therefore, the environment is inside and outside our three systems. The environment integrates these systems. Economic environment, Social environment and cultural environment are Human scale environment layers, which are only a part of the internal bigger Biosphere/ecological environment system, and where the relationships with many others living species.

We can affect the ecological environment but we cannot dominate it as does a mathematical calculation in contemporary economic perspective.

Economy is only the countable outcome of processes.

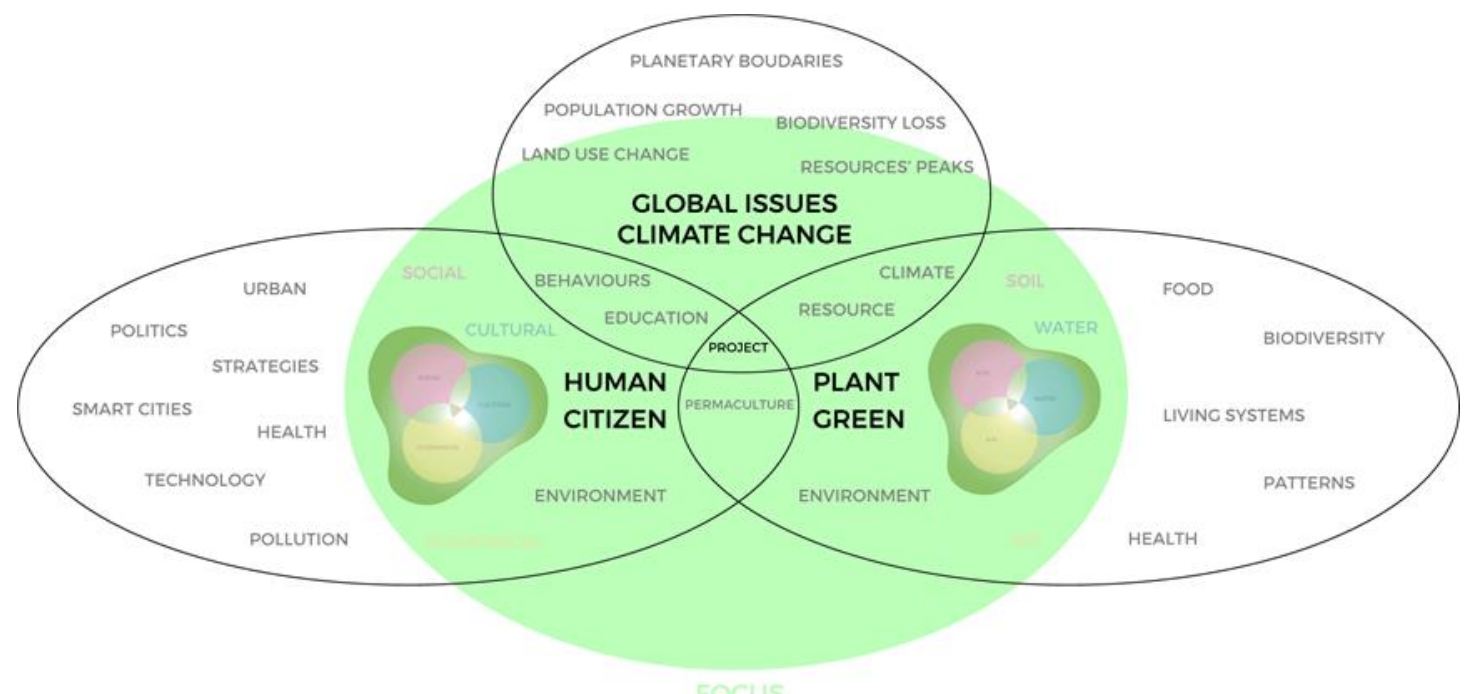

Figure 3. These convergences are going to emerge in the project outcomes.

\section{Graphic and Design: Jelena Sučić}

We cannot decide a quantity of money we want and then manage all the rest of life to achieve it.

But for sure we can identify what do we need for life and how this is going to provide for future lives, transmit the knowledge and experience to these (education building culture), the provision process involves and provides other lives (social integration) and the evaluation of how good or bad we are providing for life is economy. 


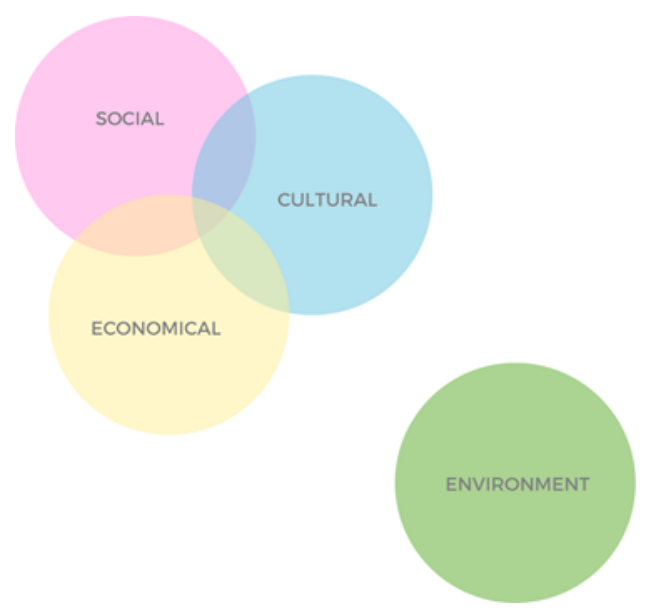

Figure 4. Environment System: New perceived system rising under human attentions that needs to be considered.

Graphic and Design: Jelena Sučić.

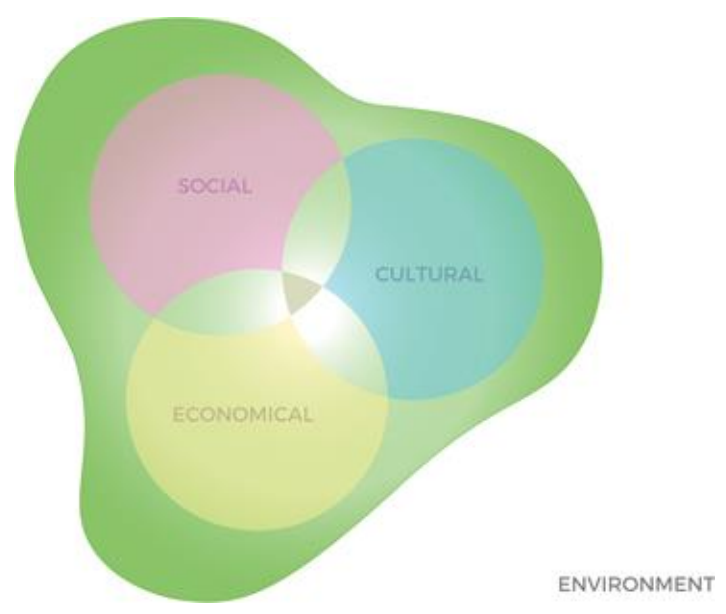

Figure 5. Needed integration for the environment system perception which has a cyclic movement from inside towards outside and vice versa.

To gain a balanced condition for a long term, human life needs to for educational paradigms that can reintegrate awareness of people's position within the biosphere. This implicates an initiation in behavioural change but also change in living culture.

\subsection{Citizens Emergence}

Citizens Urban population-culture of life systems custom flows are "threaten" by emergent environmental issues. For example, as shows well an article written by Li Jing for China Dialog: "Does Chinese public care about climate change?", based on several surveys conducted on China's national level by Governments, China Centre for Climate Change Communication and Innovative Green Development Program (iGDP) [10]. From the following results we can read the general understanding and prioritisation of citizens about Climate Change, but also a first response to react and contribute in lowering these effects by willing to apply small changes in their lifestyle in some options.

Climate Change is going to be the filter topic to explain the perceivable emergence of its effects on individual basis and citizens understanding relevance.

The emerging need of protecting ourselves, our health, relatively to air pollution is shown by the appearance of air cleaners and masks on the market. Meanwhile, there are also people looking for more natural solutions, because the first once are energy consuming and constant waste contributing. Adopted natural solutions are basically good practices and indoor plants arrangements thanks to the several lists are possible to find online, mostly derivate by the NASA reported research [11] [12]. 


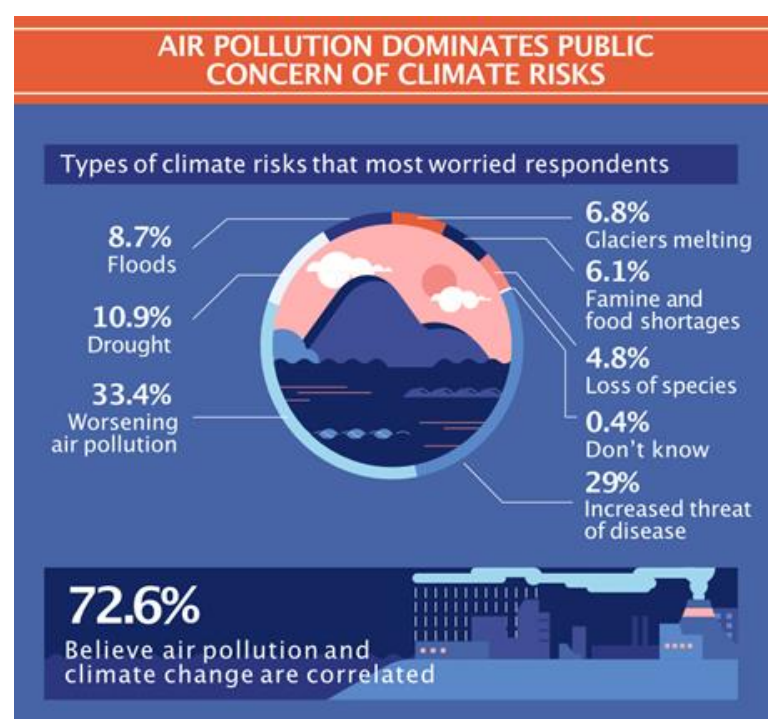

Figure 6. LI Jing's diagrams showing percentages of public's opinions about climate risks and responses of some activities on which citizens are willing to make small changes. [10]

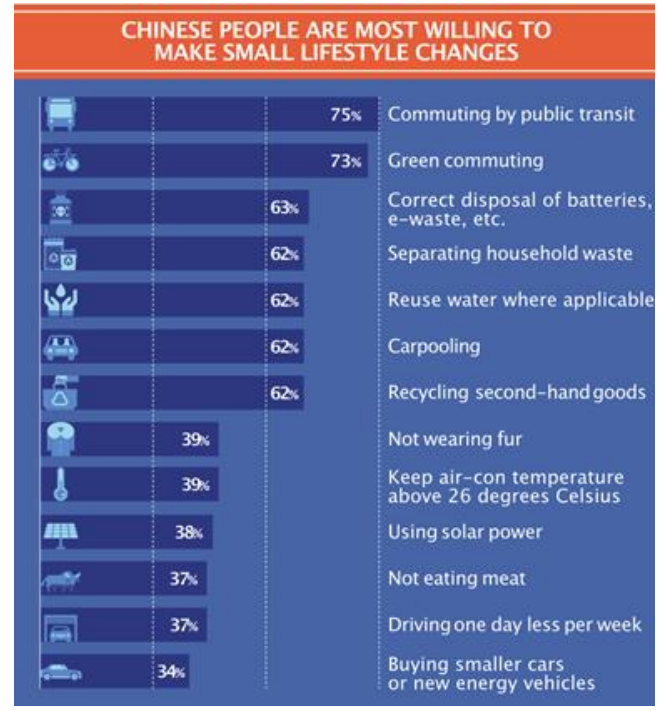

Figure 7. LI Jing's diagrams showing percentages of public's opinions about

climate risks and responses of some activities on which citizens are willing to make small changes. [10]

Something that it has to be kept in mind is that the "naturalistic approaching" on problems from citizens has two possible roots. One is the cultural background, meant as family origins and living experience. The second is a societies trend, coming from the promotion of healthy life, healthy food which it can be dated in terms of booming on public level at EXPO 2015 in Milan with the moto 'Feeding the Planet, Energy for Life!'. [13]

Natural oriented living is an established basic shared culture, maintained and developed in time. Its long-term maintenance is possible because nature processes are permanently cyclic, generation after generation/from generation to generation.

Population growth is a constant factor, even more in cities and urban areas. Contributing to this are phenomena as, Immigration, moving towards cities for better job opportunities, services coverture, etc... Which is keeping to contribute to the Use of Land changes, polluting activities, exploitation of resources, ... all of this is caused by maintaining the same production paradigm. It is already been calculated/predicted that we cannot keep going for long time in the way we have learned in the modern era till now.

UN have calculated that nowadays $55 \%$ of the world population lives in urban areas and this percentage is expected increasing to $68 \%$ by 2050 . Another their prediction is the growth of megacities number to 43 with more than 10 million inhabitants by 2030 [14]. In Europe $72 \%$ of the population lives in urbanised areas, this percentage/concentration is also expected to increase especially with the immigration flows [15]. In China there are also these trends visible in a faster rhythm than in Europe, because of its developing dynamism [16]. Extrapolated visual data from the last two references can be found in Appendix A.

These are all generation of people living detached from nature life and the awareness of what are our basic living requirements. Critical is to recognise that there is not any problem about the variety of jobs enhanced in city context, actually this 
diversification or fragmentation is positive in creating positions to be occupied assigned roles to be in charge of the needs in the functional network of the city system, but what this movement does is also distracting from what are human basic needs even if they are citizens does not mean they are not humans. The city system provides for the citizens but its source is mainly outside the urban boundary. If more humans are becoming citizens, who will produce and how will be produced the resources for the city system?

The value of those few remaining on land providing cities, has be maintained in consideration by citizens in order to support the rural system in a way that rural workers can enhance the land productivity system.

This principle cannot be only said, it has to be experienced and recognised through a significant process.

The way to shape citizens' culture, behaviour and relation with the urban environment has to change, or better, open more towards the integration and consideration of other living systems which are also our providers.

\subsection{Bigger Vision by Scaling}

If we consider the recent alarm of the IPCC special report saying we have already reached a Global warming of $1.5^{\circ} \mathrm{C}$ of the $2.0^{\circ} \mathrm{C}$ limit that we have imposed us in the Paris Climate Agreement [17], quantitatively spoken seams nothing one or two degrees more, but qualitatively we are feeling already all the effects in our comprehensible contexts. Something on what the attention on this number has to be posed, is that is an average number per year. If we consider the population perception, which lives in a determinate area the orientations are focused by comparing year periods and seasons changes between years. Mite autumns (summers extensions) in Europe with occasional very cold and strong rains. In 2016 Shanghai had the coldest memorable experienced winter in last 35 years [18] as refers to it also Helen Ni based in Shanghai and founder of the Green Light-Year NGO from the Shanghai Green Light-Year Environmental Service Center. [19] In Croatia in Dalmatia the sea has frozen, something that was not happening since half century [20]. In Bosnia Herzegovina, in the "Livanjsko polje" area, people remember on big snows and winter of $-20^{\circ} \mathrm{C}$, this does not happen anymore. Finns are living cooler winters from year to year. Japan had drastic Weather Changes making young cherry trees blooming in October-November as reported by Reuters [21] and showed through a video explanation in the social channels of the World Economic Forum [22]. This phenomenon happened because of the sequence of typhoons hit Japan, what causes typhoons is warm water un the Pacific Ocean, more about this water cycle can be found under 3.1 Climate Change Effective Principles by Using Plants.

After this little excursion, if we consider the following graph showing the glacial cycle of our planet/geologic time period when agriculture started and so the fastening of our development, it is when the biosphere has established and found constant balanced conditions defining so an equilibrium flow. 


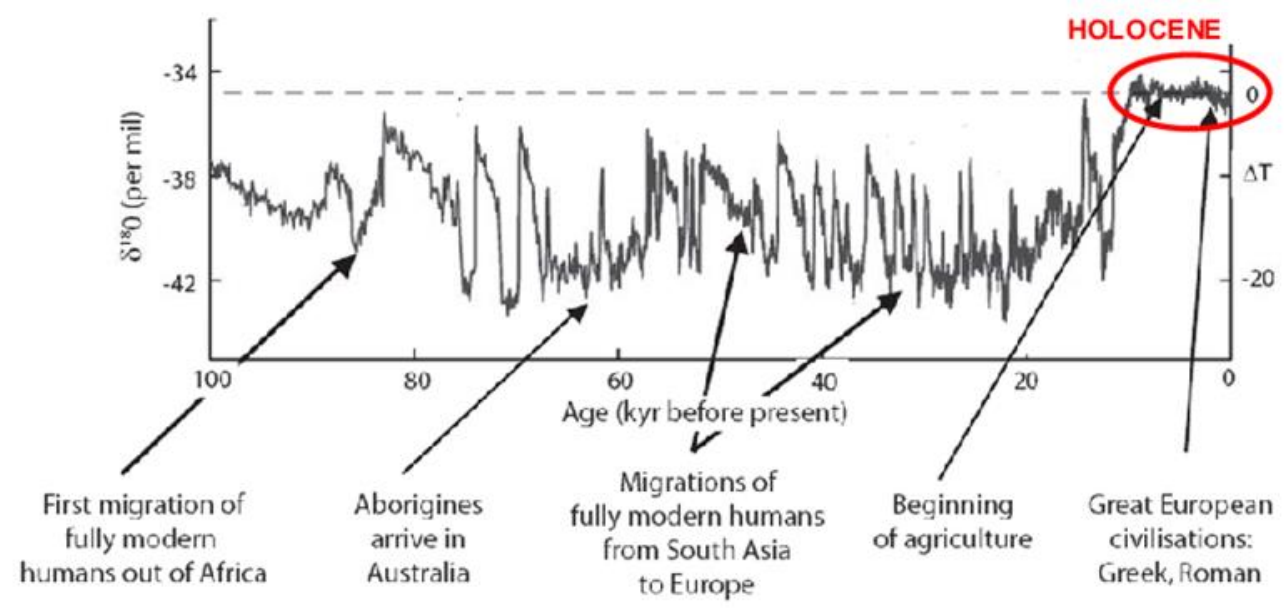

Figure 8. The last glacial cycle of 180 (an indicator of temperature) and selected events in human history. The Holocene is the last 10,000 years. Adapted from Young and Steffen (2009) [23].

This graph trend can be representative of the drastically changes perceived by a common citizen in a time scale of a year, not for nothing, weather forecasts are keeping to warn sensitive ranges of people in prevision of "heat waves" for the next day. In the entire Human existing history, there is never been such long stable period as the nowadays one called Holocene. Which is starting to be compromised by our unconsidered excesses.

We are still in a lucky era, which we do not have to abuse of.

The diffusion of small actions and relative effects has a more powerful amortisation result than few highly concentrate ones.

Therefore, a common goal or ideal with common individual actions are needed and finding the common relations and though between people/individuals contributes in building the sense of community belonging which is important to align people for the common goal.

If Quantity is Augmenting also Qualitative Reactions have to spread.

\subsection{Permaculture Role}

Permaculture is a language/discipline that reminds us how reintegrate nature in our anthropic perspective of life.

Since this term was coined by Bill Mollison and his student David Holmgren in the 1970s, it is started the definition and documentation of natural multifunctional relationships of plants, animals, insects, soil, water, infrastructure and so on, with human settlements. Before this moment and after, other analogue experiences collections were experimented by people and documented under names as Natural Farming by Masanobu Fukuoka, Biodynamics defined by the students of Rudolf Steiner, Organic Gardening, Bio-intensive, and many others, that share mainly the same principles but focused at different scales and layers.

The term 'permaculture' is integrating two meanings. The first one, as could be understood from the last sentence descriptions, is about 'permanent agriculture'. The second one is for 'permanent culture' which is human perspective oriented, refers to how to cognitively coexist with nature and the human applied approaches towards this aim which have an accumulated culture through time and is going to 
keep building knowledge and applications responding to the future challenges. [24] [25]

A semester project about Open Systems (overview of the project Appendix B) made face the need of understanding natural processes and the followed permaculture training of 12 days given by Wayne Weiseman [26] [27] last summer plus more focused courses in the urban and house environments which sessions were hosted by Rainbow of Hope Project organisation [28] , allow to enter in a language dynamic to describe experiences, document them and making them accessible in terms of understanding to common citizens, and comprehend principles as design bases where to develop creativity in resolutions. The principles are going to be explained and scaled for a common urban contemporary dimension and understanding.

The roles of permaculture in this research and design process are the understanding that Permaculture is integration design of human needs with natural processes and because of its biological and ecological base permitting the widely comprehension of the sustainability concept.

If we consider that sustainability is mainly meant as "fight against waste", to manage this issue a reminder of possibilities is needed, in fact Zero Waste in biological is possible because of the life cycle process, and this helps in understanding the meaning of pollution. "Pollution is a product not used by something else; it is an over-abundance of a resource [29]" basically is a resource not absorbed by the (eco) system.

From documented experience we can define measurable parameters to help us recognise these behaviours in future experiences. This process defines the language to talk about nature experiences, share and compare them.

Why focusing on plants? They are primary producers providing and working in strict relationship with the three natural/matter flow systems and with living organisms being part of any of Nature Kingdoms.

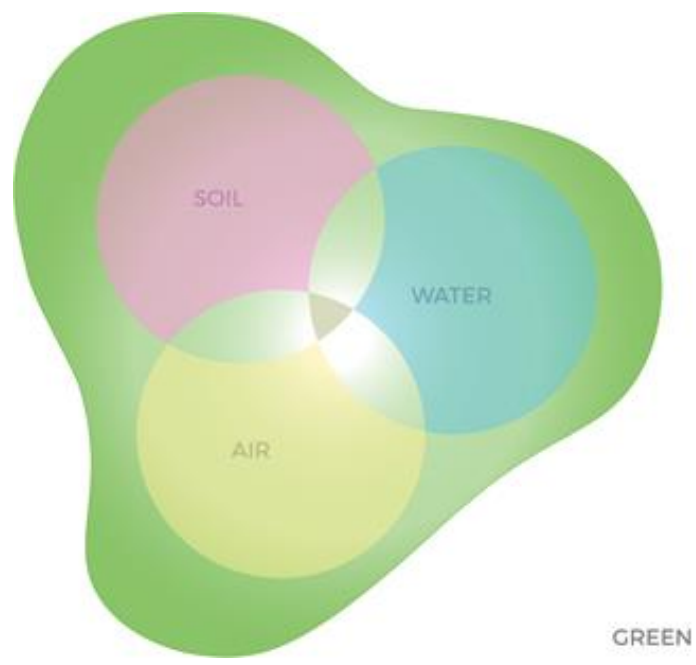

Figure 9. Green meaning the Plants Community or Vegetation starts from and contributes to the three natural source systems Soil, Water and Air.

Graphic and Design: Jelena Sučić.

\section{Discussion: The Need to Define Contextual Parameters}


In order to focus for practical goals in small dimensions it is important to define some parameters or a language to describe the positioning of actors' actions to follow the movements of their effects in different scales, layers and levels. Being able in this way to have a comprehension from the whole picture to focused happenings. The main considered actors are Citizens and Green. Green because is already in a considerable strict relation with the three main nature cycles air/atmosphere, water, soil. By re-establishing a more aware relationship with Green, Citizens are per consequence relating with the three mentioned nature systems.

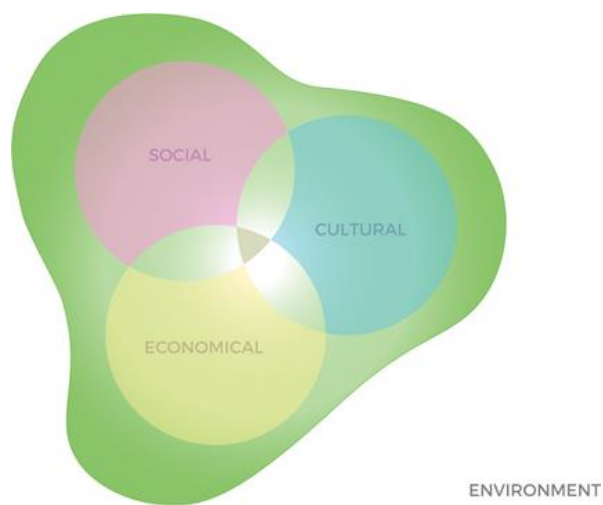

Figure 10. As the Citizens perceived systems are Social, Cultural and Economical starting from the Environment and being included by it.

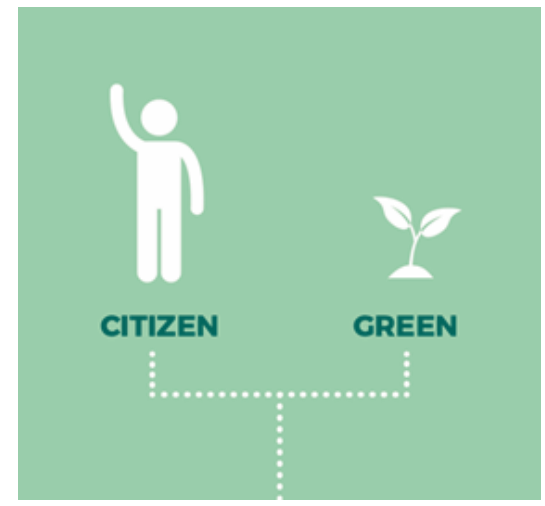

Figure 12. Two main actors' citizens \& green.

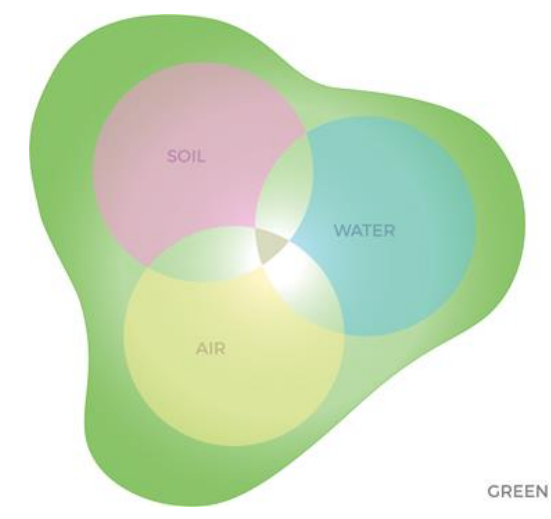

Figure 11. Green starts from the three natural source systems Soil, Water and Air and includes them in its growth processes.

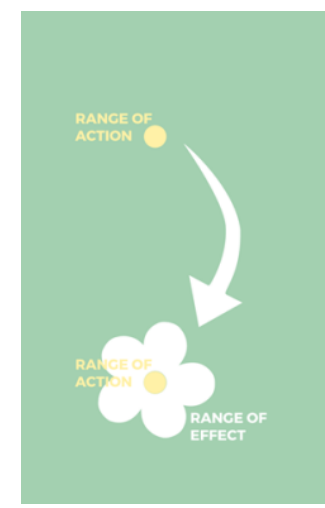

Figure 13. Two ranges of the actors: Range of Action and Range of Effect.

\section{Graphic and Design: Jelena Sučić.}

The range of action is really focused meanwhile the range of effect has many factors that will determine the effects diffusion. For example: Positioning a seed is a very circumscribed action but the process of growth of it will be directed by factors as space, sunlight, nutrients, water, wind, circumstances will show if the yield is healthy, big, weak, nourishing other organisms, how many of them, seeds spread, etc.

To enhance the relevance of actions even if small the comprehension/consideration of the whole picture is necessary. To orientate in a given context we need to define it therefore to recognise its relevance with other conditions or relation with contexts. Once we want to position a condition (individual element) or context (group of elements), it has to be kept in mind that we are stopping in a moment in time. 
Scales have a spatial movement as showed in the exemplary sequence of illustrations under Figure 14.

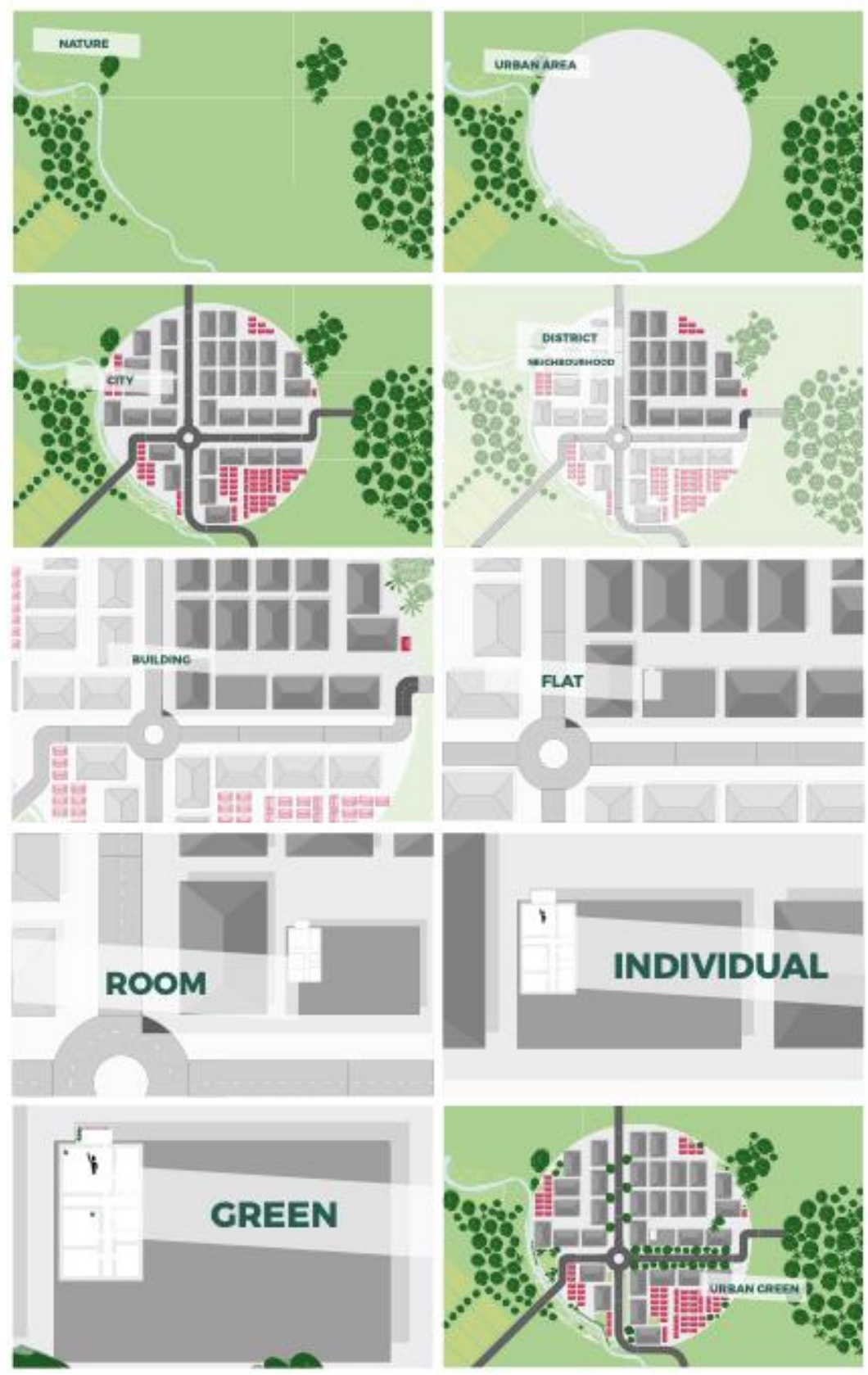

Figure 14. Sequence of illustration of the scaling spatial movement.

Graphic and Design: Jelena Sučić.

Layers are defined contexts from different perspectives present inside the scale dimension and according to the layer we are referring to its impact in the space and read that is different from others. Inside the layer there are elements with different levels of relevance as explained briefly with the example under Figure 15. 


\section{LAYERS \& Levels}

INSTITUTIONAL

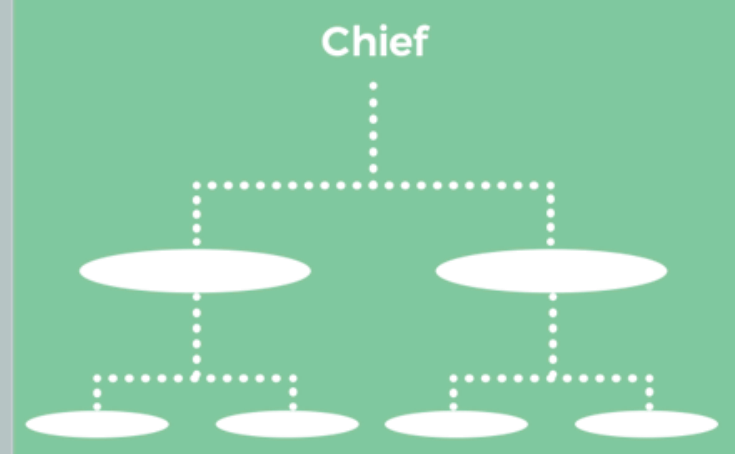

COMMUNITY

INDIVIDUAL

Figure 15. Some examples of identifiable layers and levels movement dynamics per relevance.

Graphic and Design: Jelena Sučić.

Some recognisable dynamics are: institutional (governances), perceptional (citizens) and naturalistic (permaculture).

Layers are practically creating groups according to the considered context definitions. By defining our considered context in this way, we can understand and follow what are the groups and how their building is affecting the others the environment in the scale of pertinence. Therefore, also the impact of the single elements in the group towards the including and surrounding environment of them.

The word environment is very often used as a synonym of ecology, but there is a little detail in the etymology of the particle 'eco' from Greek 'oĩ ${ }^{\circ} \varsigma^{\prime}$ ' means 'house' intending the English word 'home' [30][31]. By defining a space 'home' we are declaring a sense of belonging towards it. In fact "Ecology is the branch of biology which studies the interactions among organisms and their environment [30]".

Talking about environmental issues or ecological issues on a city scale, the mainly considered layer is the institutional one of the governance and their high-level departments chiefs. By interviewing these highly politically positioned people adapting for climate changes is the main vision of cities and on the same time their main complain for doing it is that there is a lack of education and resources, money and people. Interviews reference in Appendix C.

But if this is the priority, on what are the resources going?

\subsection{Climate Change Effective Principles by Using Plants}

In Chinese east (coasts) big cities context, Climate Change most publicly considered effects are air pollution affecting health, heat flows exchange and floods causing soil erosion, water losses and built infrastructure damages. Climate change is also considered the cause of the rise of Oceans' water levels. In order to understand the potential of small spread actions the following illustration will show the cyclic 
cascade effect starting from dust as air pollutant in a micro scale. This effect is explained by Wayne Weiseman [32] and the figure illustration is based on his explanation, Figure 16.

If we manage already to allow this happen as much as possible we are contributing to the alleviation/mitigation of climate change effects relatively to air pollution. To recognise the effectiveness of these illustrated cascades a refreshment of common relative nature cycles may help and follows.

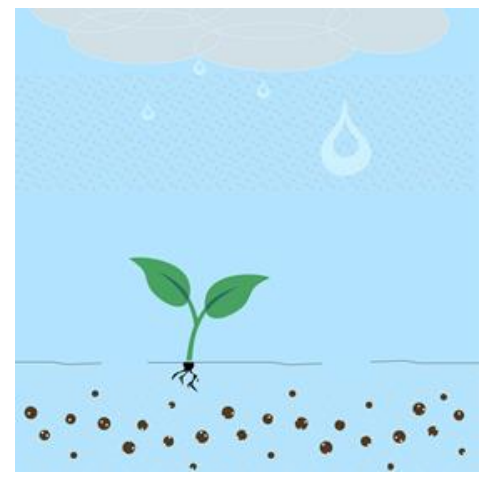

The Dust in the air phenomena defined as Pollution is a mixture of Particular Matter which is composed by several potential minerals and organic matter for the soil.

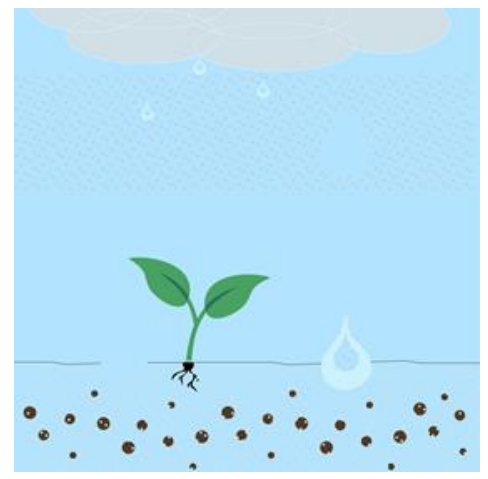

When it rains the water drops by falling capture the particles with them to the ground. The surface structure is going to direct the rain fall deposition or flow circulation.

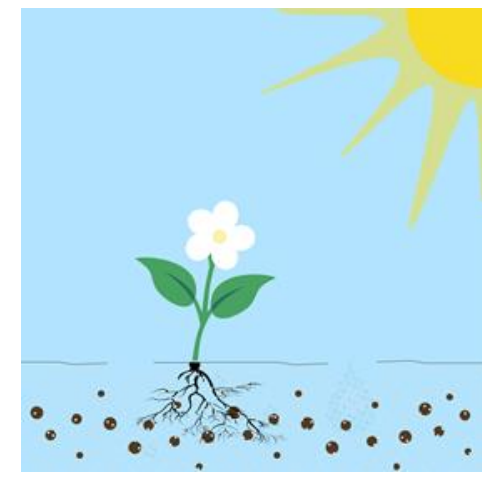

The rain drops penetrate in to the structure of the soil bringing the minerals and organic matter with them enriching the soil. Plants root systems looking for the water are going to absorb some of these.

Figure 16. Illustration sequence of the cyclic cascade effect starting from dust as air pollutant in a micro scale.

Graphic and Design: Jelena Sučić.

\subsubsection{Hydrologic cycle}

The water presence in the biosphere appears in three shapes vapour, liquid and solid, and it keeps to change trough processes shown in the diagram, movements that are all powered by the sun's heating energy which affects according to the structure of the context. The temperature and humidity effects we perceive are all the results of the constant moisture exchanges between the three nature cycles air, water and soil.

Recovering the water in depth land layers is part of the cycle process we have to improve also in bigger scale and especially in the urban scale, to avoid letting it run off directly in the oceans and deposit there. The depositing effect is allowed by the water permanence, which if it is more than the quantity the surface exposed to the sun heating action to move up with evaporation process the remaining water molecules are going to be "attacked" by salt molecules making them gain weight and acquire density, this defines a layer of water with a specific salt concentration. This phenomenon determines oceans water layers which corresponds to the climate memories deposited in water for centuries and millenniums [33] and also the oceans level rise that is contributed by an excessive water income in a period of time that the sun cannot make evaporate all in that time. Meanwhile the remaining water has been attached from salt molecules, which means that that water needs more sun energy to be heated. If we put the salt in the pot before the water is boiled for the pasta, this 
water will take longer to boil because it needs more energy to reach the boiling temperature.

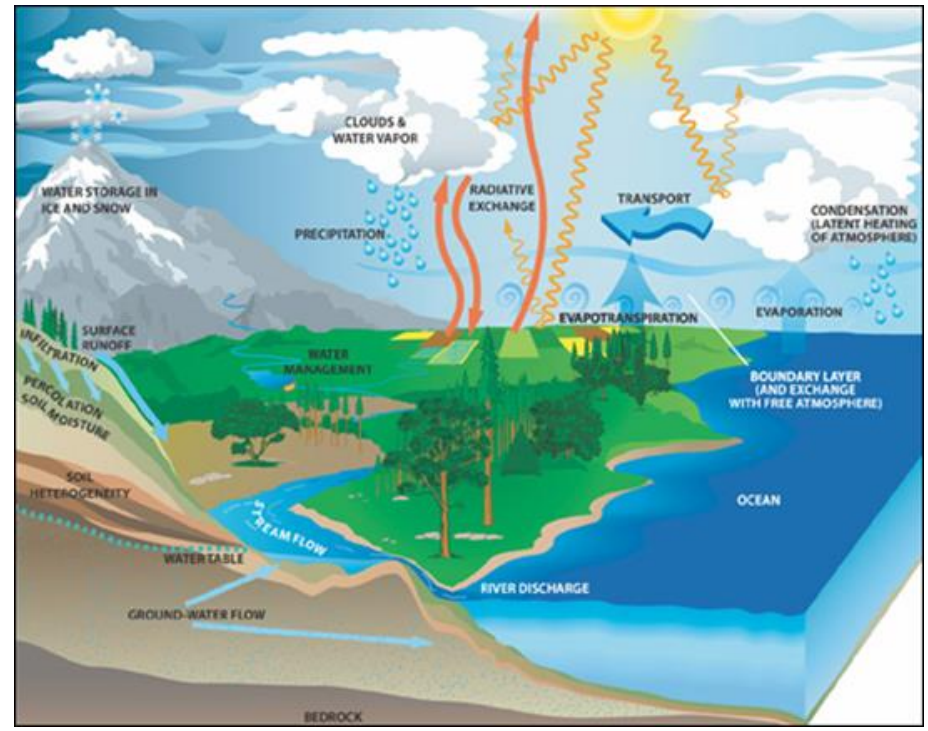

Figure 17. "Credit: NASA GSFC Water and Energy Cycle web site. This diagram shows the relationship between Physical Oceanography, Biological Oceanography, and Water Cycle.

Feedbacks between Physical Oceanography and Water Cycle are Evaporation minus

Precipitation and Fresh water transports (i.e. Goldsborough Circulation). Biological in the ocean is affected by the water cycle via the Mixed Layer Depth and Run off from land. Finally, feedback

between Physical and Biological Oceanography include the sea-ice and haline [34].

\subsubsection{Forest Intercept water cycle}

The Forest intercept the rainfall through its layers levels and structures. The rain drops slow down once they fall on a leaf and following leaves or branches, till they end into the ground. Some of the water will be kept by the soil structure and some will pass the evapotranspiration process which in terms of steps means that compared to bare land where the water that arrives will not have to pass through all those layers, soil, leaves, branches in vapour form, and not passing all these layers the evaporation process is direct and requires less time. At every layer there is an evaporationcondensation process that starts again, extending so the water permanence time.

Because of this the forest system affects the climate creating its own micro climate, improves the air quality because of the plants photosynthesis process and the cascade effect illustrated in Figure 16.

The forest provides shelter and food for creatures, its root system stabilises the soil, preventing soil erosion and landslides [35], on the same time slows down winds [36].

The opposite phenomena of floods are droughts and happen basically because the ecosystem structure was not able to retain the water arrival opportunities. For this reason, permaculture design principles work a lot with the landform [37] by creating swales and similar structures. Another detail to keep in mind is the 'water attraction factor' is about what does initiate the condensation process, it happens when the vapour water particles in the atmosphere suddenly hit towards a cooler temperature sphere as the forest sphere is comparing with the city sphere. To summarise, forests are rain attractors.

\subsubsection{Modern Agriculture Industry}


As understood during the first phase of research about the actual linear production system in the Open System project (Appendix B) where emerge all the critical issues of the resources supply for intensive monoculture production models. They are based on chemical industries (chemical processes emissions an energy requirements), not local suppliers (transportation and logistics effects), the production process is focused on few products but on massive quantities, seeds and treatments are designed as a package, sterile seed, pesticides (contribute to kill the balancing effect of biodiversity), chemical fertilisers (synthesis of $\mathrm{N}, \mathrm{K}, \mathrm{P}$, in a form that the plants are not able to absorb properly, causing an excessive presence of them becoming pollution), soil exploitation (ample flat land from which always the same nutrients get absorb by the mono crop conducting to the condition to prevent self-recovering) and inefficient watering systems, are just some of the main effects. Another pushing factor for all of these is the global market paradigms pretend standards of quantities, qualities and safety (medical safety controls make enhance the 'cleaning' process of pesticides). As last the 'abundance' life standards rooted in the so called developed countries asks more than what is actually necessary motivate the market requests and initiate a wasting process.

\subsubsection{Lifestyle}

The choices and adaptations of our lifestyles affect the effects of all the abovementioned development processes. Our diet, our land use in purpose and way of managing it, resources directing and producing, through behaviours. Transportation needs dictate our decisions and behaviour, and so the effect of the happening. As has showed already the Figure 7 under 2.1 Citizen's Emergence. Nutrition need do the same, people chose what to eat and so all the behaviours and effects of the production chains. Slow Food Movement is doing a great job in building the awareness in consumers about food choices and their effects also in relation of Climate Change [38]. An interesting concept explained by Valtero Canepa is Carlo Petrini's though, founder of Slow Food, is about being a "co-producer". "A co-producer is a consumer who knows and understands problems of food production: quality, economics and processing requirements, the culinary aspect. It's not just someone who consumes. It's that they want to know [39]."

Many studies have been done about the food choices effects and how these can contribute to mitigate climate change and contributing in developing sustainable behaviours stimulating sustainable production requirements. A recent study mentioned by Kate Whiting in an article on WEF [40] refers to options from food system choices that might contribute a sustainment actually facing environmental boundaries [41].

Many effects depend only on consumers/common citizens education.

\subsection{Education Paradigm}

A very common concern from governances about environmental issues when you ask them is that there is a lack of education in citizens (Appendix $\mathrm{C}$, mentioned already in the end of 3.Discussion: The Need to Define Contextual Parameters). From this opinion considered as a fact rises a question which is: Why?

For sure many studies are been done to answer at this question and have tried to propose solution and develop projects for the response. 
This research tries to contribute in giving this answer and the first step stays in enhancing the general condition of the actual official educational system that structure the learning process of youth at schools. By talking about education and educating the level of who is in charge of this activity is higher than of who is going to be educated.

It happens that the institutional educational format in classroom has a predominance of linear movements and the kinds of media used are exclusively visual and oral.
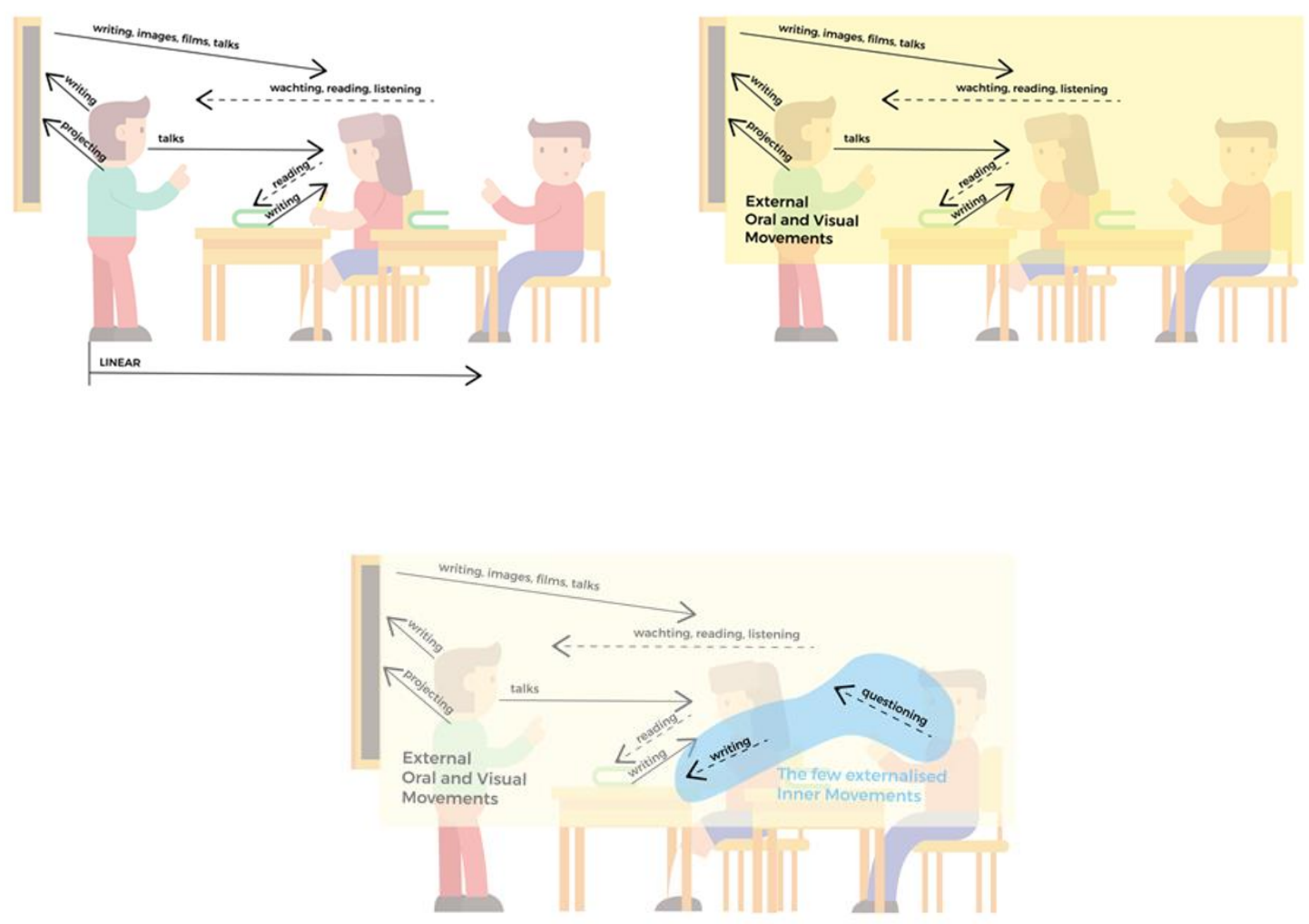

Figure 18. Illustrated sequence of the information media in a classroom, showing the predominately linear movement and top-down visual and oral kinds.

There are only few inner movements allowed in this structure:

I. Writing/drawing notes that activates a tactile movement and externalise the absorption of the lecture and re-elaboration of the information in an own understandable pattern;

II. Questioning does externalise as well the lecture absorption but in an active oral movement stimulated by an internal elaboration aiming for a feedback that can organise or align the information patterns.

We do not know if this is the right way of educating, teaching transmitting something we have just decided it is. So how do we explain those students in a classroom that do not get in that 'traditional' way? Another question is about those that get things with the traditional path how long are they going to keep them in mind? 
To raise knowledge level of students more dynamic contexts may help in stimulate more externalised inner movements allowing the building of knowledge patterns [42] in each individual. It is all a system of feedback loops as defined by cybernetics that build the structural dimension of relationships in our brain and is a science basing on animal control and communication processes to build the machine ones [43]. Cybernetics stays on the base of the information organisation build in complex technological computing which are inspired on human information organisation processes. The only difference is that the machine's information is build step by step by humans, action that is tried to be done also with educational programs which have the defect of dealing with uncontrollable open systems (people's mind) that have life and experiences also outside the classroom (influenced by untraceable environmental circumstances), therefore outside the educator's observation range. By moving towards humanism another interesting definition mentioned by Humberto R. Maturana in "the Art and Science of Understanding", together with Francisco J. Varela define cognition and coined the term autopoiesis [44] to explain biological intelligence, life plus production. 'Bio' standing for 'Life' an 'logy' or logic' referring to 'dialog', refers to we the audience of life dialogs, including lives filled with experiences deciphered in a language. In order to recognise the referring experience of a spoken language, associations in some principles needs to be found to find matches with our knowledge patterns. The associational thinking, especially if multiplied, is a training that we have forgotten to exercises in our current life modern days mental elaboration processes.

Sometimes some good educators do explain by changing from the high level of language of that matter to an example in daily life/common level of language or by giving example of same principles in different contexts. This association movement catches the attention of the 'new entries' in the matter and permits the escalation to the higher level. This same movement is required when a high levelled group of people in a matter meets, but their background experience of how they acquired that knowledge is different.

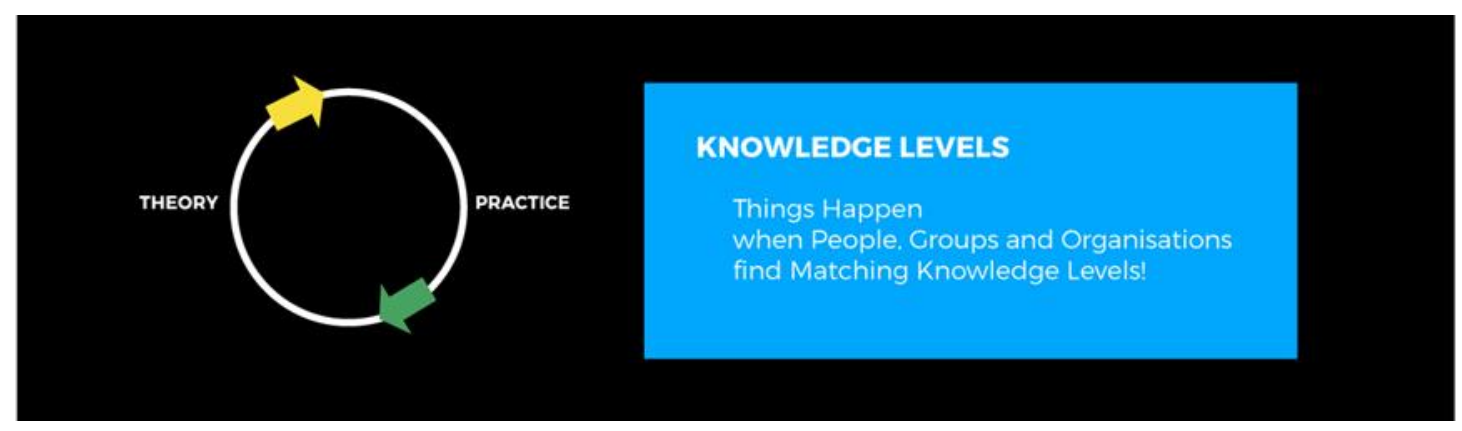

Figure 19. Graphical explanation of Knowledge Levels inside a project context under the Creative Systemic Research Platform Team. Design: Prof Susu Nousala [45].

Graphic Design: Jelena Sučić.

In the transmitting processes of experiences and knowledges generational perspectives have to be kept in consideration. The highest generations in age levels have experienced differently a determinate context because the culture of perceiving it has changed in time and so the language of explaining the acquired knowledge.

The language has always to adapt to the context, the cultural environment, age of the audience, background experience of the knowledge. 
After considering all these aspects more matching knowledge levels [45] provide chances common experiences to happen.

The empirical observation is what allows our intuition to find a focal point of research in any specific discipline/field.

Finding relations between things is a complex and dynamic process, which requires time, experiences, a lot of observations and considerations, but endures longer, even in our memory. Time fractions include all the mentioned actions in longitudinal cyclic developments in a group dynamic [46]. That is proven by integrative educational approaches and designing immersive experiences as "learning by doing", Waldorf education and Finnish educational system.

In order to assure understanding, continuous exchange moments in layers and levels have to be provided.

An education paradigm shift is needed, or at least exercise dynamism of creating openings (associations) from the traditional order to catch the elements differently and then integrate them in the aligned traditional language.

Linear (instruction [42]) is short-term, you lose a term, you lose the reliability of the information. Dynamic (network of associations) is long-lasting, you lose an association, the network will keep the principle on which you can build again.

\subsection{Case Study Scenario + Concept Design}

The conducted research wants to support the relevance of a bigger and long-term series of project actions leaded by the CSR Platform [47]. There are two main currents moving on. The first one wants to physically activate the intangible community building process with several elements under the structure/hut of a Film Symposium.

The second current works on a physical Life Lab under the name Laukku House, building research networks collecting and providing tangible results and data for future generations from and for any background. Used tools will have the common aim in innovating in educational structures and contents, in which is been recognised the emergent need to contribute in the paradigm shift of it, especially to respond widely towards climate change issues and sources.

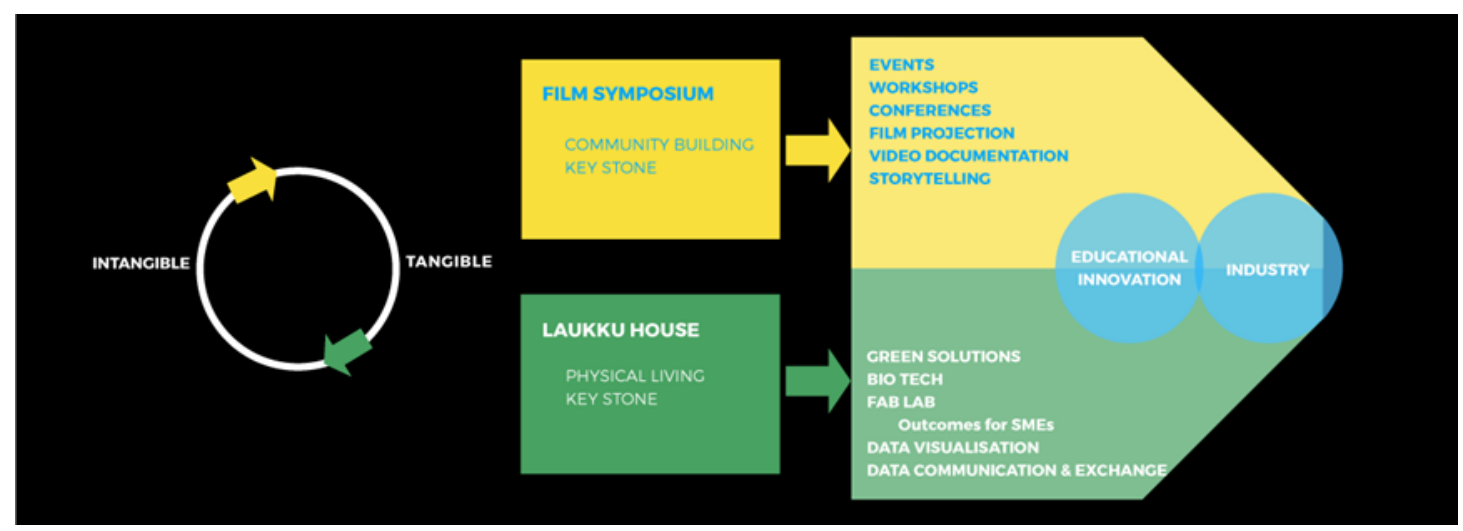

Figure 20. Graphical explanation of the two macro currents of projects planned by the Creative Systemic Research Platform Team.

Design: Prof Susu Nousala; Graphic Design: Jelena Sučić.

The component on which this side of research wants to focus on a concept named Laukku Pod, a focus of studying, documenting living ecosystems behaviours. It is a 
scalable lab structure that is based on creating and recognising functional relationships between plants which are primary producers, working in strict relationship with all other organism and matter cycles (explained in 2.3 Permaculture Role).

Plants communities are systems that citizens have stopped to consider in last decades and from this mis-consideration are emerging the basic principles of all our environmental issues, as explained already in part (3.1 Climate Change Effective Principles by Using Plants) and what more the next steps are going to explain.

Laukku Pod has a physical structure as a base, which is a closed or open environment, which can be provided to the user or can be self-defined. It is connected to monitoring sensors and a digital platform of users where the research results and documentation are shared. The service system can provide the documentation structure and tools to allow any user to design experiences, contribute and refer to already done researches. There is a team working on plant systems modules based on permaculture principles and documentations as to provide starting points for who wants experiment with plants for their different functions. There are several conditions that might affect the developments of the ecosystem, that can be installed anywhere in the world and ate every scale, and paying attention to them by documenting will permit us to prevent not meant alterations in the future settings. Working with Nature does never provide absolute results, is not a dogma, we can only learn through research and experience how to set the best conditions for our aim and needs accomplishment. Learning to adapt to change is a citizen's challenge nowadays in order to respond towards sustainability goals and plants have multiple hidden potentials in their life cycle that is beyond the nice aesthetics. Plants living process are the most sustainable technologies that any citizen can rely on to contribute in mitigating environmental issues at any scale, starting from our homes and offices to the biosphere. In order to rely on these green technologies a longitudinal documentation process and aligned language to aliment is necessary and because of the recognisable detachment of the new citizens generations from nature, everybody that is willing to share what still knows or has learned from grandparents has to be able to access at this documentation process. The allowance of variety in community members in layers and levels has the richness to providing experiences from different bioregions and providing scientific deep research inspirations form a long-term experience documented by a common citizen that has learned from grandparents 'tested' plants combinations. Another reason why everybody may be able to join is that the value and knowledge of the living systems providing for our lives is getting forgot very fast, therefore to do not lose it has to recover fast and widely spread also in youth/younger out coming generations so to assure at least a few more human life cycles of permanence.

Nature driven experience learning process from early stages can be upgraded constantly, by maintaining the relation with it. Questions, associations and consideration rise with it, extending the coverture that is moved by the need of comparing experiences to verify own ones. For this reason, the Laukku Pod branch has also a section dedicate to knowledge building systems in which educational programs for schools with experimental lab contexts are included.

This process and topic has a predisposition to humanising science, a common citizen does not necessarily need to know all the specific chemical reactions allowing plants functions to work in certain conditions as it might be interested to study about a biologist or a chemist, but recognising that a combination of plants contributes to 
clean the air or repel from mosquitos or enhances the growth of their basil (pesto lovers) does interest and it makes them discover new plants and new useful usages of them. So, this emerging potential of combinations permits to recognise Innovation in visualising integrated natural principles and functions as Sustainable Technologies. Technologies that are providing us: food, filtering air, filtering water, reconstructing the soil, structuring the soil, medicines, therapy, creativity inputs, inspirations and new lives creation.

\section{Conclusions}

It may seem that all the content of this research is inclined to say stop with the New Technologies, as Artificial Intelligence, Machines,...This is not true. All these technologies are helpful in understanding and emulating nature processes to help us to manage the overwhelming effects of last century's human activities and developments. They really help us in documenting experiences and knowledge in a way that can reach many more minds than we would be able to do by our owns, without languages, printing technologies, transportations, photography, drawing with different kind of media, internet meeting points, and so on, we could share and compare our experience and knowledge only with the people we know in our tribe.

There is a warning/reminder behind all the enhanced points, which is about the fact that humanity cannot rely only on their new technologies, as the urban society rhythms are tempt to do, because all the new technologies rely on natural resources and if we do not contribute to their regenerative processes, and we keep to obstacle them, on a certain point of time without knowing it, referring especially on masses, because the awareness of this strict relation is been stopped to be transmitted, the biosphere will feel collapsing and humanity will struggle even more than now.

Individual experiences are very valorised in this research because those allow to find alignments with others, contributing so to a group knowledge. Therefore, the design process wants to allow integration of multiple layers and levels of people kinds and plants kinds.

Plants living processes are dynamic resources with a constant cyclic providing process, able to respond to the emergence of climate change related issues, the knowledge generational gap and the need of redefining the educational paradigm.

The documentation of plants communities' feedbacks may contribute to the research of new emerging science studies as 'neurobotany' initiated by Stefano Mancuso [48] and robotics inspired by plants network structures [49].

By understanding basic nature processes, training us to scale them in different contexts with our own different background, we can observe associations in principles in our daily life, and by visualising them we can innovate contributing so to train creativity in problem solving.

Why is important to experience things? In order to define them with a language we can recognise.

Science is a highly methodological language to describe an experience in order to be able to repeat it several times and obtain the same results.

Art tries to express a feeling/impression/interior experience to the outside world moving in a scale of greys between abstraction and concrete. 
Design does start from a background knowledge to planning or setting the circumstances for the happening of an experience, this process allows to open Science circles and associate Art feelings with others.

\section{Conflicts of Interest}

The authors declare that there is no conflict of interest regarding the publication of this article, at the current moment.

\section{Appendix A}

Data tables/graphs

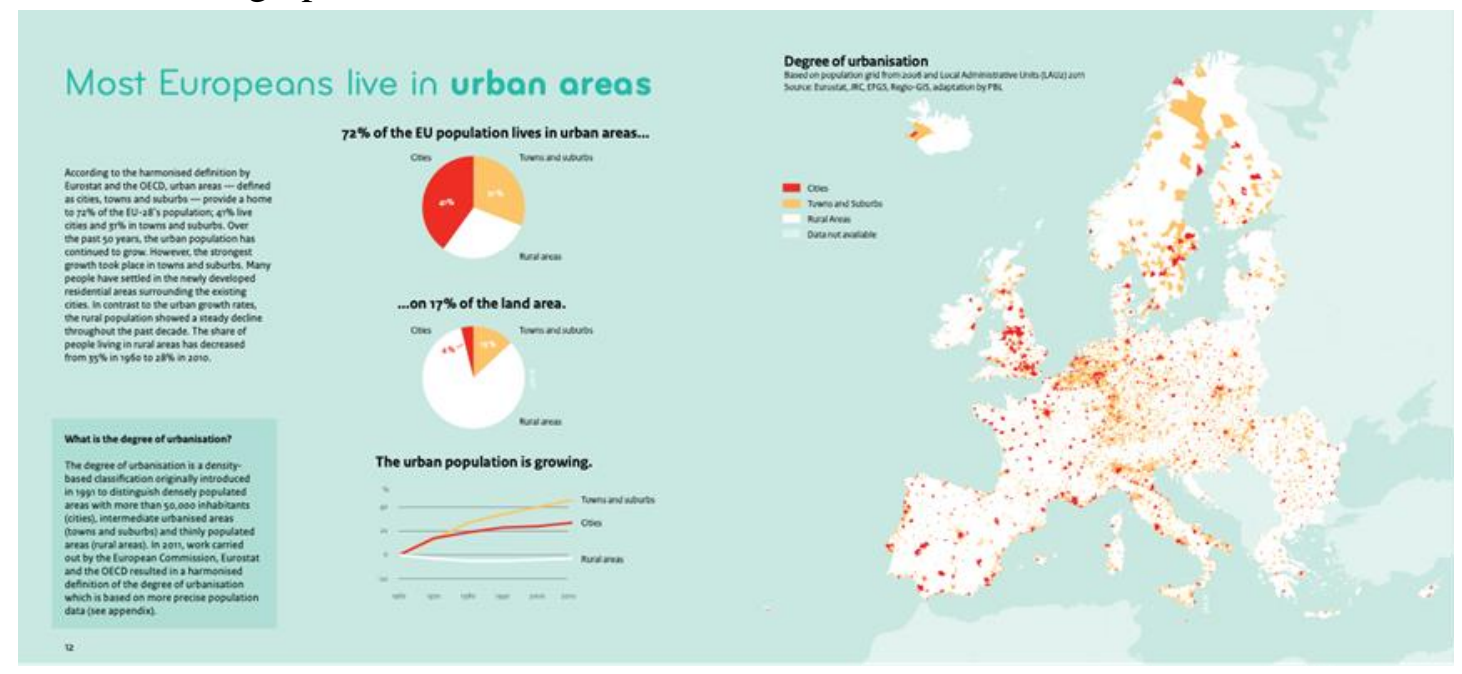

Figure A1. Data visualisation showing European population density extrapolated from the document: Cities in Europe. PBL Netherlands Environmental Assessment Agency [15].

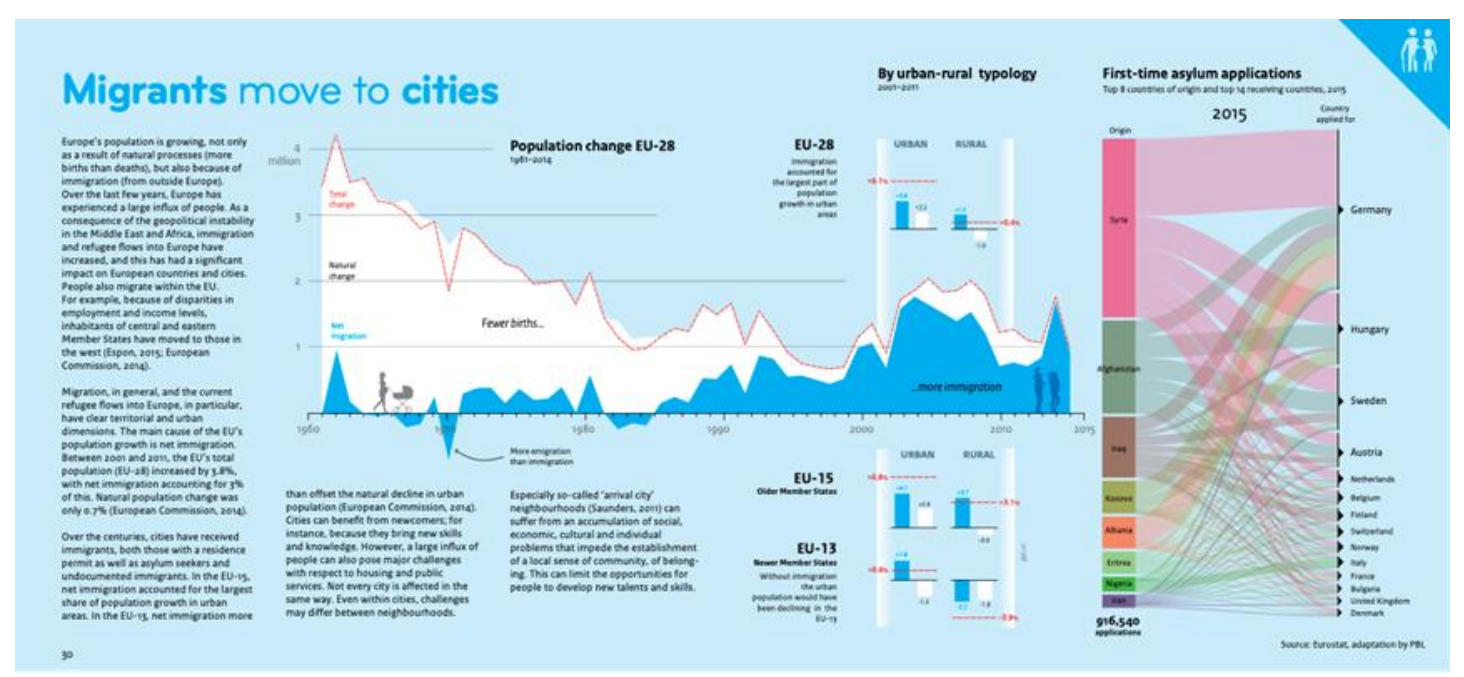

Figure A2. Data visualisation showing European Migration compensation in population extrapolated from the document: Cities in Europe. PBL Netherlands Environmental Assessment Agency [15]. 


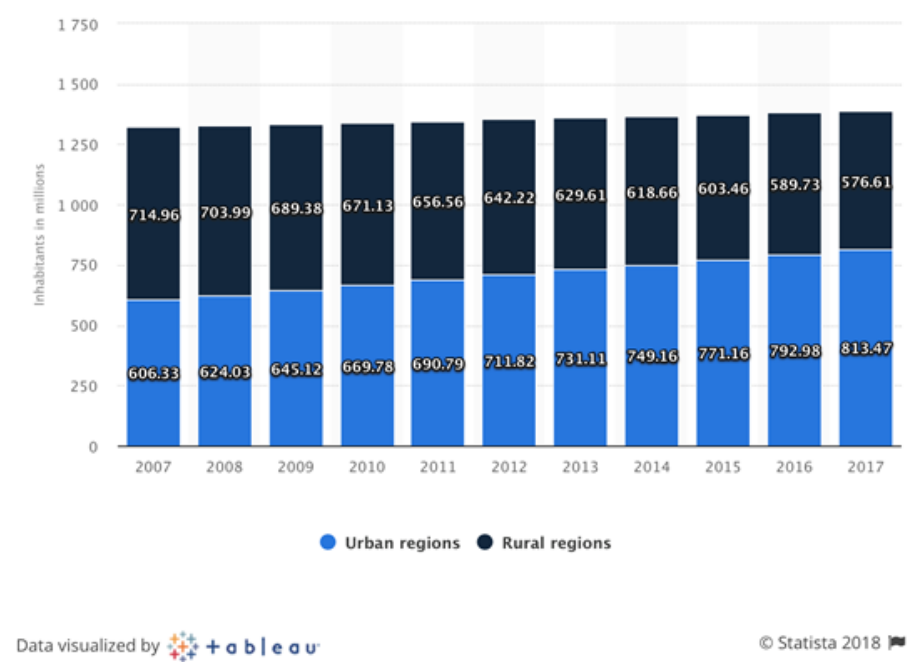

Figure A3. Trend of the Urban and rural population movements of China from 2007 to 2017 (in million inhabitants) [16].

\section{Appendix B}

Open Systems course spring semester project 2016/2017, MSc Master Degree Course in Systemic Design, Politecnico di Torino, Prof. L. Bistagnino, Prof E. Comino, Prof. B. Pedone, Prof. P.P. Peruccio. The author Jelena Sučić was part of the class project. In the project the students were asked to redesign the basic productions chains fruits\&veggies, cereals, milk and meat in the South Rural area of Torino in a much sustainable way than the actual situation. By analysing the local territory and valuing its proprieties and traditions the class was able to propose long-term production modules for that specific territory. For achieving this, students had to acknowledge by themselves about permaculture, bio-dynamic agriculture, synergetic farming and other analogue practices. Through the research and the acquired knowledge, the resources flow with the activities systems could be designed with the Systemic Approach in the way to create functional relations and transforming outputs in inputs.

The whole production modules were redesign based on the researched permaculture principles, the territorial contexts, cultural traditions, local resources availability, local diet models, seasonality, etc. Crucial conclusion emerges from this entire research, out of the fact that the nowadays cultural, social, economic paradigms have to change in order to reach sustainable conditions, but especially the integration of production lines with forest systems. Brief Selection of tables follows.
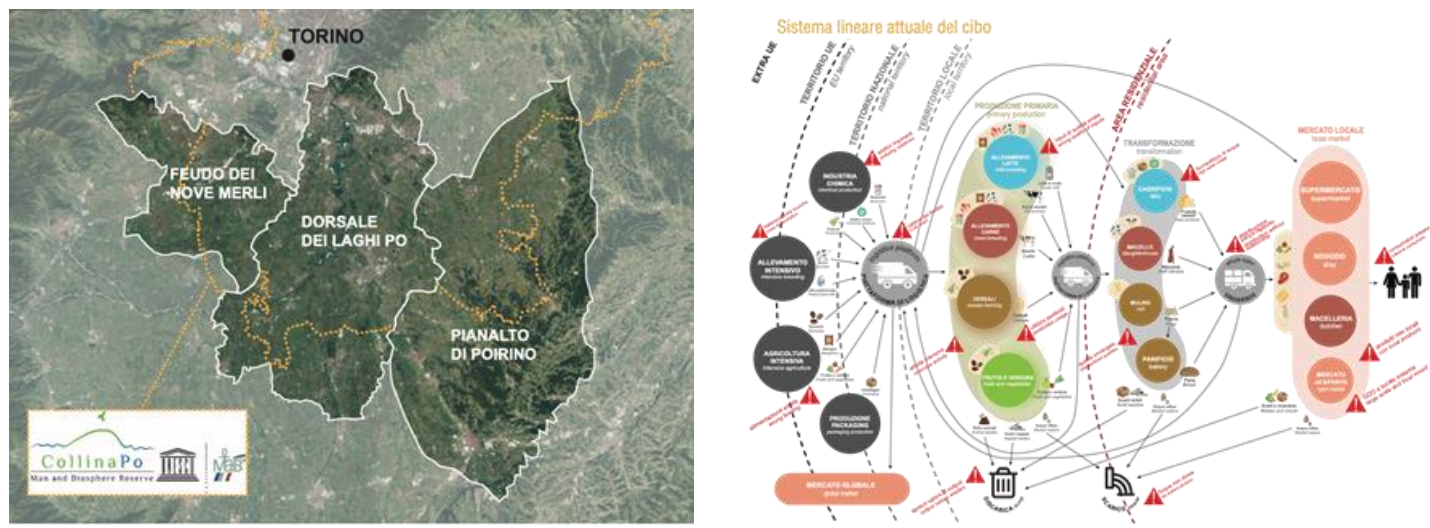
Figure B1. Three territories location in Italy.

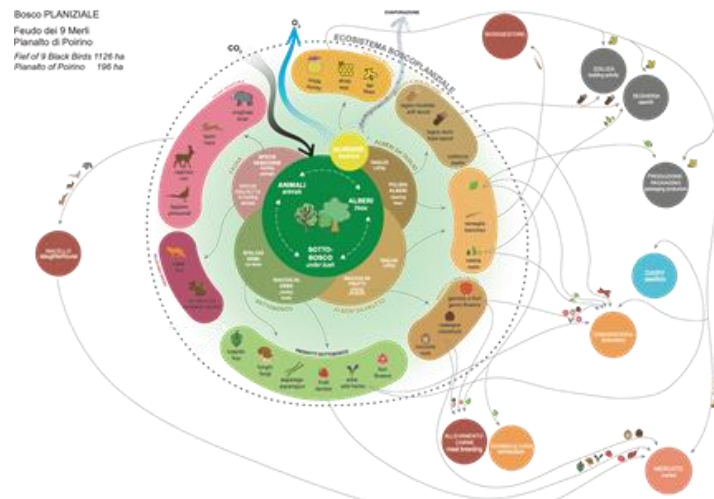

Figure B3. Plain Forest system model designed by the Open Systems class 2016/2017.

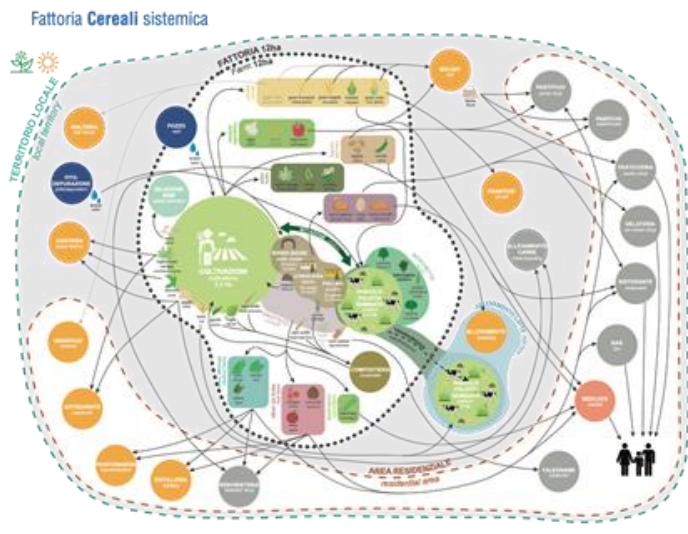

Figure B5. Sample of systemic farm mainly Cereal producing. Spring-summer season.
Figure B2. Actual linear system, flows and criticalities.

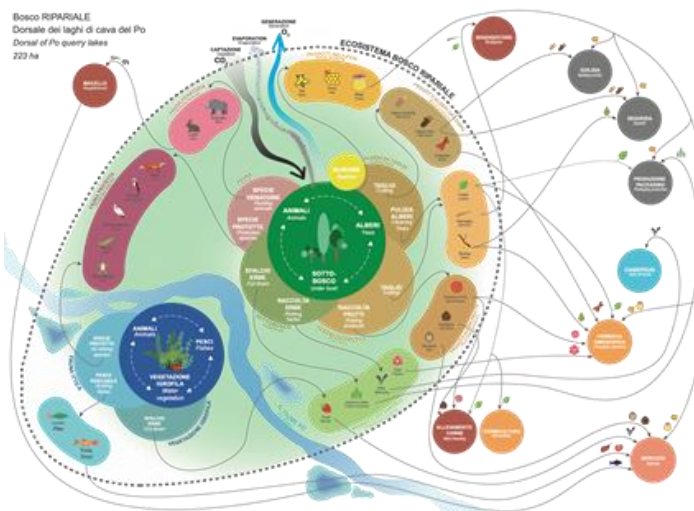

Figure B4. Riparian Forest system model designed by the Open Systems class 2016/2017.

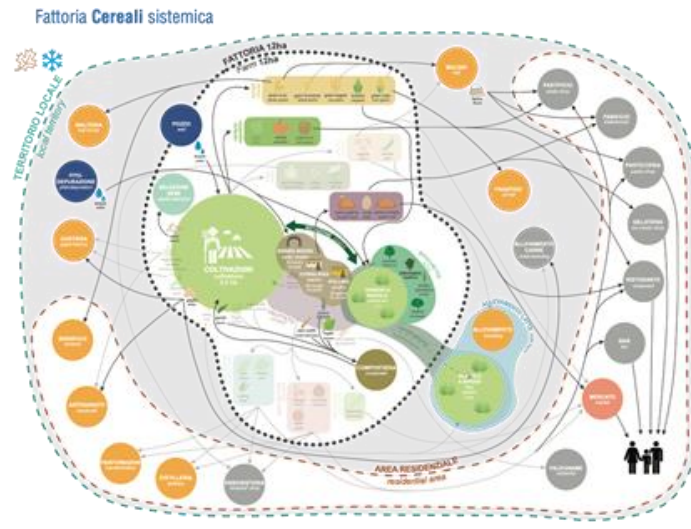

Figure B6. Sample of systemic farm mainly Cereal producing, Autumn-winter season.

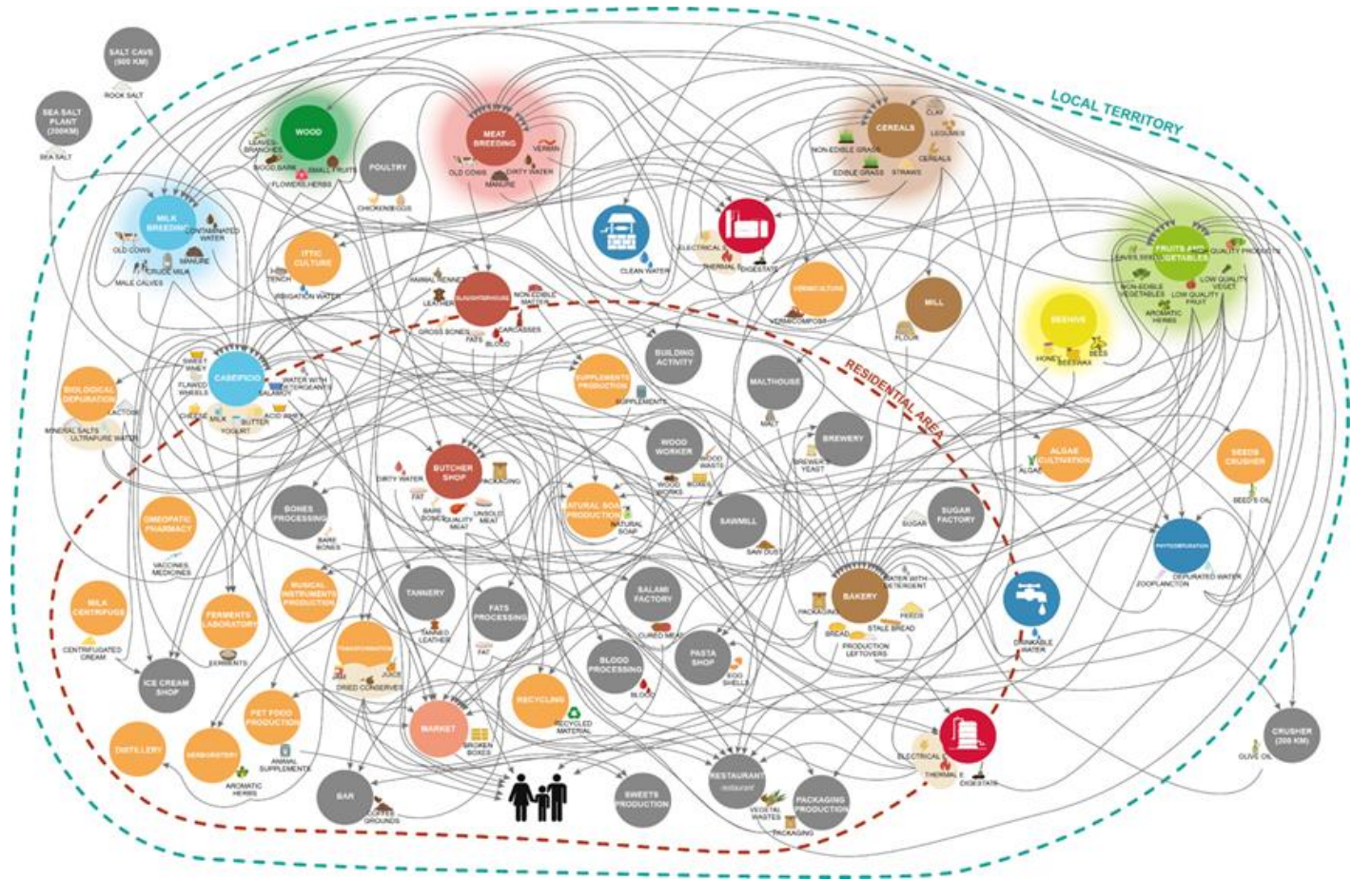


Figure B7. Macro-system of relationships design in the Local territory. The apparent chaos in lines actually stands for stability given by the strict integrations of actors' roles and resources supply.

The Semester Project has been developed further as a thesis by two colleagues, Alessandro Maccagno and Amedeo Mascitti.

* Mascitti, Amedeo and Maccagno, Alessandro

Applicazione dell'Approccio Sistemico in tre territori siti UNESCO a sud di Torino $=$ Systemic Approach applied ot three UNESCO sites located on south of Turin.

Rel. Pier Paolo Peruccio, Luigi Bistagnino, Giuseppe Pedone. Politecnico di Torino, Corso di laurea magistrale in Design Sistemico, 2018. Available online: https://webthesis.biblio.polito.it/6701/

"Systemic Design project regarding the food supply chain of Pianalto di Poirino, Dorsale dei laghi del Po e Feudo dei Nove Merli territories; with constructed economical models and systemic farms. (translated brief description from URL*)."

\section{Appendix C}

\section{Interview resume by questioning Urban Green Sustainability}

Follows resume of relevant aspects emerged from the interviewed figures in Torino City context, enhancing considerable positive and critical aspects.

Assessore Unia is the new head of Environmental Administration of Torino. The city is recognising now the need of a strategical plan of the urban greening, the Vision is to manage the Climate Change, research required for the introduction of new more resistant plants, lack of money and people for the maintenance, Green Print project for mapping all the city green in order to understand the present resources for implementing where and in the way is needed, usability of green areas and recreational green. Social aspect to valorise and citizens education. The city has always worked on this but it seems to be enough for help and integration. Geological predisposition, the city already has a developed green system but never been strategically applied. It is historically and traditionally always dedicated to gardening, so much that Torino was the first city establishing a City Gardening School, an education program to rise gardeners for the city service. [a][b]

Michela Cacalano, Representative of Torino ProGIreg, an EU international project explains the research aims of these experiments based on Natural Based Solution (NBS) which are working on Innovative usages of the urban green and developing Solutions for urban regeneration, three big aspects are:

1. 'New soil' concept (analogue to the brownfield practice)

2."Verde diffuso"/ 'Diffused Green' (aquaponics, green rooftops, ...)

3. Cross activities: citizens involvement and sensitisation (social component) [c]

A representative of Torino Città Metropolitana, institution that deals with regulator plans and their approvals, provided last regulations about urban greening and signalised a lack of interdisciplinary approach from the several offices for developing sustainable strategies.

Emilio Soave of Pro Natura Torino Association, he is a veteran expert of Torino's Green History in all its aspects. This entity works practically trying to remedy on 
municipalities failures or inattentions, also thought from citizens perspectives. The city closing parks to prevent security issues for the citizens. Trees have a big cultural and traditional value, indeed there is a green service office dedicated only on Trees' management, where at the moment there is in charge person with a totalitarian and not integrative approach on change, old architectural culture perspective of symmetry. This one has to stay under the directives of the Ministry of Cultural Heritage because some historical trees and boulevards are protected. This create 'un-reaction' effects and another factor that contribute on this are plants species illnesses. The example was: five horse chestnuts with white flowering have been cut from a boulevard area and not replaced because that specie is vulnerable to 'Cameraria Orhidella', citizens ask to replace them with anything because of the emptiness and the sun exposure. What did the City? Nothing. Why? Because lack of knowledge, adaption and of course money and human resources to be able to choose to react. An adaptable solution is given by our figure, that considers all the pre-explained blocking factors: substitute with horse chestnuts of the same family, but the once with pink flowers which is not vulnerable.

Dr. Ippolito Ostellino, ex member of Torino Internazionale Association and ex coordinator of the group about 'Green Infrastructure', which was one of the topics that wanted to define a strategical plan for the metropolitan green, inside of Torino Strategica project which was involving all 38 municipalities of the Torino Metropolitan Area. All the association was working on metropolitan strategic plans which stopped after the new politician's entrance in Torino City Administration. Explicative materials were produced and are still available online. The booklet about the green infrastructure is highly communicative in contextualised and shared approaches, values, priorities, cultural landscape, actual situation, resources, ... It integrates EU commission guide lines which want to define greening from the sustainability point of view giving this new name Green Infrastructure. $[d][e][f][g]$

A summary is given by the following explained schema from Dr. Ostellino: it's all in a golden rectangle and these elements will favour natural ecosystem to do their duties: Ecosystemic Services.

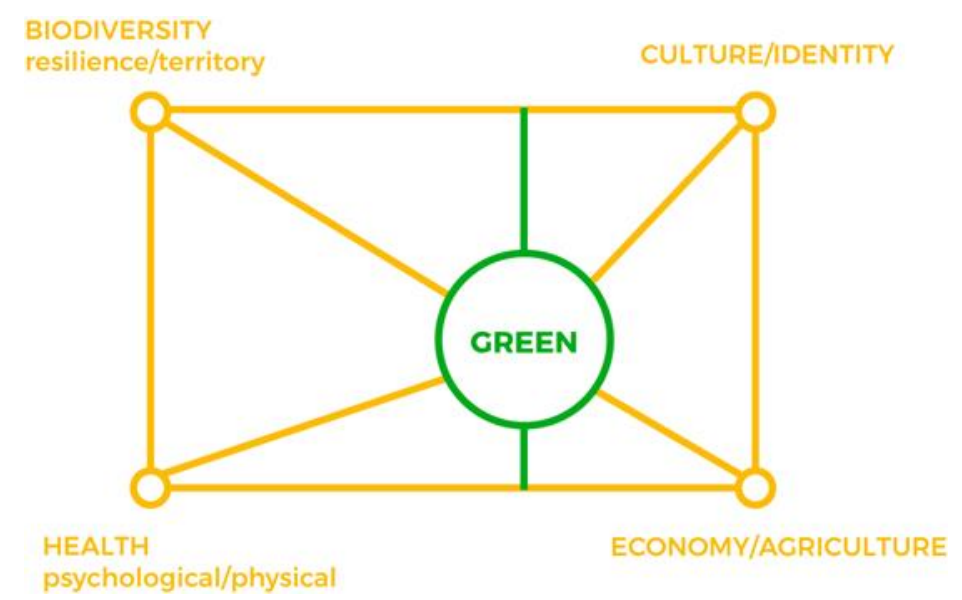

Figure C1. Graphical transposition of the theories and elememts shared by Dr. Ostellino about the planes intended to be applied through the Torino Strategica project.

Other crucial points from his perspective as naturalist and manager of Parchi Collinari Collina Po and other green structures in the metropolitan area are: 
a. Small (actions, strategies in greening) but multiplied many times is much more manageable in terms of dimensions but for achieving long term efficiency a 'middle facilitator organism' is needed, 'Island effect' has to be avoided;

$b$. Architectonical order culture: linear, in contrast with the diversity order of Nature;

c.Italian political culture with self-blocking predisposition;

d.Italian environmental legislation problems from the base: not really reactive;

e.Absence of naturalists, biologists, geologists, which are experts of nature systems in green political action groups, are considered only, agronomists, gardeners, which are professions of nature transformation. There is a fundamental problem in recognising the difference, and how integration of both is needed;

f.Citizens Hierarchical not understanding of Nature presence:

- in function: human leisure activity grass dedicated area and the grass area of spontaneous ecosystems (not kept short);

- in time: people exist on Earth since 200,000 years while insects exist since 500,000,000 years;

- in kind: we are only one of the species under the Animalia kingdom, which only one of five and we all have to live in the same Earth, environment, home.

\section{Some available internal references from the outcomes:}

[a]Città di Torino, Verde Pubblic, Available online: http://www.comune.torino.it/verdepubblico/index.shtml

[b]A. Vanzo, Giardini d'artista sotto la Mole: Storia del Servizio Giardini di Torino e delle opere dei giardinieri - Tratradizione e smart city, Available online: http://www.comune.torino.it/verdepubblico/2016/altrenews16/giardini-dartista-sottola-mole-un-libro-racconta.shtml

[c]ProGIreg project, Available online:

http://www.comune.torino.it/verdepubblico/2018/altrenews18/parte-il-progettoeuropeo-progireg-le-tecnologie-n.shtml

[d]Torino Metropoli 2025, Terzo piano strategico. Available online: http://www.torinostrategica.it

[e]Quaderno Infrastruttura Verde: CORONA VERDE 2015, Available online: http://www.torinostrategica.it/pubblicazioni/corona-verde-2025/

[f]European Commission, Green Infrastructure (GI) - Enhancing Europe's Natural Capital, Brussels, 6.5.2013 COM(2013) 249 final, Available online: http://ec.europa.eu/environment/nature/ecosystems/docs/green_infrastructures/1_EN_ ACT_part1_v5.pdf

[g]The Multifunctionality of Green Infrastructure, Available online: http://ec.europa.eu/environment/nature/ecosystems/docs/Green_Infrastructure.pdf

These are all examples of what comes out from experts' voices about Sustainable Urban Greening in Torino, Italy, context. So many points emerged, only by asking about this topic, which allow comparing with other realities from desk-research finding commons and differences and how these differences can be sources of solutions in other urban contexts. 
Interviews records and transcript available on request. Note: They are all in Italian.

\section{References}

[1] Kadim, Isam; Mahgoub, Osman; Baqir, Senan; Faye, Bernard; Purchas, Roger. Cultured meat from muscle stem cells: A review of challenges and prospects. Journal of Integrative Agriculture, 2015, 14(2), 222-233. Available online: https://www.researchgate.net/publication/272522939_Cultured_meat_from_musc le_stem_cells_A_review_of_challenges_and_prospects (Accessed on 20 November 2018).

[2] 'Development' has several meanings according to the context as explained on Cambridge Dictionary. Available online: https://dictionary.cambridge.org/us/dictionary/english/development (accessed on 20 November 2018).

[3] World Commission on Environment and Development (WCED), (1987), Our Common Future (Brundtland Report), Oxford University Press, Oxford. Available online: http://www.un-documents.net/our-common-future.pdf (accessed on 20 November 2018).

[4] Refering to K. Boulding with The Economics of the Coming Spaceship Earth, 1966 and to R. Buckminster Fuller with Operating Manual for Spaceship Earth, 1969.

[5] World Economic Forum, Cristiana Pasca Palmer, The world needs to live up to promises made on biodiversity. Here's how, WEF, 02nd March 2018.

Available online: https://www.weforum.org/agenda/authors/cristiana-pascapalmer (accessed on 13th November 2018).

[6] Jorgen Randers; Johan Rockström; Per Espen Stoknes; Ulrich Golüke; David Collste; Sarah Cornell. Transformation is feasible, How to achieve the Sustainable Development Goals within Planetary Boundaries, A report to the Club of Rome, for its 50 years anniversary 17 October 2018, Stockholm Resilience Center, October 2018. Available online: https://www.stockholmresilience.org/research/new-planetary-boundaries.html (accessed on 10 November 2018).

[7] The Global Goals for Sustainable Development. Available online: https://www.globalgoals.org (acceded on 10 November 2018).

[8] Inspired from L.Bistagnino's Introduction, Design for a New Humanism in: L. Bistagnino, F. Celaschi, C. Germak, Man at the center of the project, Design for a new Humanism., Umberto Allemandi \& CO, 2008. ISBN: 9788842216292 8842216291.

[9] 'Environment', Definition from Cambridge Dictionary. Available online: https://dictionary.cambridge.org/us/dictionary/english/environment\#dataset-cald4 (accessed on 20 November 2018).

[10]LI Jing. Does the Chinese public care about climate change? China Dialogue, 21.09.2018.

Available online: https://www.chinadialogue.net/article/show/single/en/10831Does-the-Chinese-public-care-about-climate-change- (accessed on 29 September 2018). 
[11]B.C.Wolverton, Anne Johnson, Keith Bounds, Sverdrup Technology, Interior Landscape Plants for Indoor Air Pollution Abatement Final Report, NASA John C. Stennis Space Center Science and Technology Laboratory, September 15, 1989.Available online:

https://ntrs.nasa.gov/archive/nasa/casi.ntrs.nasa.gov/19930073077.pdf (accessed on 3 December 2017).

[12] Bored Panda, NASA Reveals A List Of The Best Air-Cleaning Plants For Your Home. Available online: https://www.boredpanda.com/best-air-filteringhouseplants-nasa (accessed on 3 December 2017).

[13] Milano Expo 2015. Available online: http://www.expo2015.org/en/ (accessed on 20 November 2018).

[14] United Nations Department of Economic and Social Affairs. 68\% of the world population projected to live in urban areas by 2050, says UN, 16 May 2018, New York. Available online:

https://www.un.org/development/desa/en/news/population/2018-revision-ofworld-urbanization-prospects.html (accessed on 18 November 2018).

[15] Nabielek K. et al. (2016), Cities in Europe. PBL Netherlands Environmental Assessment Agency, The Hague. ISBN: 978-94-91506-97-0. Available online: https://www.pbl.nl/sites/default/files/cms/publicaties/PBL-2016-Cities-inEurope-2469.pdf (accessed on 18 November 2018).

[16] Urban and rural population of China from 2007 to 2017 (in million inhabitants) (Created with Highcharts 5.0.14). Available online: https://www.statista.com/statistics/278566/urban-and-rural-population-of-china/ (accessed on 18 November 2018).

[17] Report, Global Warming of $1.5^{\circ} \mathrm{C}$, an IPCC special report on the impacts of global warming of $1.5^{\circ} \mathrm{C}$ above pre-industrial levels and related global greenhouse gas emission pathways, in the context of strengthening the global response to the threat of climate change, sustainable development, and efforts to eradicate poverty., October 2018. Available Online: https://www.ipcc.ch/2018/10/08/summary-for-policymakers-of-ipcc-specialreport-on-global-warming-of-1-5c-approved-by-governments/ (accessed on 20 November 2018).

[18] That's Mag, Cathy Wu, -10 This Weekend, Coldest Shanghai Winter in 35 Years, January 20, 2016.

Available online: http://www.thatsmags.com/shanghai/post/12135/town-criershanghai-s-coldest-winter-in-35-years (accessed on 11 December 2018).

[19] Wei Xuanyi. Environmental Enthusiast Promotes Low-Carbon Lifestyle. Available online: https://mp.weixin.qq.com/s/ruVk_WWLz1cAcPVGAaQtCw (accessed on 5th December 2018).

[20]Pictures of the frozen sea in Dalmatia are available under the following article: index.hr, I.Ra, Ovakvu Dalmaciju još niste vidjeli: Zaledilo se more, automobili i brodovi, 7.1.2017. Available online: https://www.index.hr/magazin/clanak/fotonestvarni-prizori-iz-ledom-okovane-dalmacije-zaledilo-more-automobile-ibrodove/942567.aspx?fbclid=IwAR3SNIBV6Q6WeLco4q4sxC97JUq0Q8tFokMoTXe0MysCgoClavSJAcG8rM (accessed on 10 January 2017). 
[21] Tim Kelly. Tickled pink: Typhoons trick Japan blossoms into blooming six months early, Reuters, OCTOBER 18, 2018. Available online: https://www.reuters.com/article/us-japan-cherry-blossoms/tickled-pink-typhoonstrick-japan-blossoms-into-blooming-six-months-early-idUSKCN1MS0WQ (accessed on 18 October 2018).

[22] World Economic Forum, Recent typhoons have caused Japan's cherry blossoms to bloom six months earlier, 18th October 2018. Available online: https://www.weforum.org/agenda/2018/10/tickled-pink-typhoons-trick-japanblossoms-into-blooming-six-monthsearly?utm_source=Facebook\%20Videos\&utm_medium=Facebook\%20Videos\&u tm_campaign=Facebook\%20Video\%20Blogs (accessed on 18 October 2018) .

[23](PDF) Planetary Boundaries: Exploring the Safe Operating Space for Humanity. Available online:

https://www.researchgate.net/publication/42766179_Planetary_Boundaries_Expl oring_the_Safe_Operating_Space_for_Humanity (accessed 2 December 2018).

[24]B. Mollison; D. Holmgren. Permaculture ONE: A Perennial Agriculture for Human Settlements, Tagari Publications ed. 1990, 1st 1978. ISBN: 0908228031.

[25]D. Holmgren. Permaculture, Principles \& Pathways Beyond Sustainability, Permanent Publications, UK, 2011, p. xix. ISBN: 9781856230520.

[26] W. Weiseman, D. Halsey, B. Buddock, Integrated Forest Gardening, The Complete Guide to Polycultures and Plant Guilds in Permaculture Systems, Chelsea Green Publishing, White River Junction, Vermont, 2014. ISBN: 978-160358-497-5.

[27]Permaculture Project. Available online: http://www.permacultureproject.com (accessed on 5 January 2019).

[28] Rainbow of Hope. Available online: http://www.rainbowofhope.cn/permaculturetraining (accessed on 5 January 2019).

[29]Bill Mollison's Permaculture Design Certificate Course, Course Outline, Section 2: Principle of Natural Systems and Design, Permaculture Institute, p. 2.

[30] Wikipedia. Available online: https://en.wikipedia.org/wiki/Ecology (accessed on 13 December 2018).

[31] Wiktionary. Available online: https://en.wiktionary.org/wiki/oíkoৎ (accessed on 13 December 2018).

[32]W. Weiseman; D. Halsey, B. Buddock, Integrated Forest Gardening, The Complete Guide to Polycultures and Plant Guilds in Permaculture Systems, Chelsea Green Publishing, White River Junction, Vermont, 2014, 126-127, ISBN: 978-1-60358-497-5.

[33] G. Beltrando, Les climats, processus, variabilité et risques, Armand Colin, Paris 2004, 56-58, ISBN : 2-200-26238-8.

[34]NASA Earth Science: Water Cycle. Available online: https://pmm.nasa.gov/education/articles/earth-observatory-water-cycle-overview (accessed on 5 December 2018).

[35]Legambiente Piemonte e Valle d'Aosta e Regione Piemonte, Manuale del Bosco...ma non solo, Regione Piemonte, November 2008. Available online: 
http://www.regione.piemonte.it/foreste/images/files/pubblicazioni/manuale_bosc o.pdf (accessed on 5 December 2018).

[36]B. Mollison, D. Holmgren, Permaculture ONE: A Perennial Agriculture for Human Settlements, Tagari Publications, Great Britain, ed. 1990, 1st 1978, p. 43, ISBN: 0908228031.

[37]B. Mollison, Permaculture: A Designers' Manual, Tagari publication, 2nd ed. 2002, 1st ed. 1988, 319-335, ISBN 0908228015.

[38] Slow Food, Menu for Change, Paper furnished by Valtero Canepa from Slow Food Shanghai, Convivium Leader, during a lecture at Tongji University, 24th May 2018, Available online if registered: http://slowfood.com/joinus (accessed on 5 January 2019).

[39]Petrini, C. 2007. Slow food nation. New York: Rizzoli Ex Libris. ISBN: 9780847829453.

[40] Kate Whiting. The unbelievably simple way to cut greenhouse gas emissions in half, WEF, 26 Nov 2018. Available online: https://www.weforum.org/agenda/2018/11/want-to-save-the-world-become-aflexitarian/ (accessed on 27 November 2018).

[41]Marco Springmann; Michael Clark; Daniel Mason-D'Croz; Keith Wiebe; Benjamin Leon Bodirsky; Luis Lassaletta; Wim de Vries; Sonja J. Vermeulen; Mario Herrero; Kimberly M. Carlson; Malin Jonell; Max Troell; Fabrice DeClerck; Line J. Gordon; Rami Zurayk; Peter Scarborough; Mike Rayner; Brent Loken; Jess Fanzo; H. Charles J. Godfray; David Tilman; Johan Rockström \& Walter Willett. Options for keeping the food system within environmental limits, Nature 2018, https://doi.org/10.1038/s41586-018-0594-0. Available online: https://www.nature.com/articles/s41586-018-0594-

0.epdf?referrer_access_token=IcRVAEZpHyH6RgWRAhQFkNRgN0jAjWel9jn R3ZoTv0M2ZckU8PFAjFp2beHrcOXhHVPwiboHFjCLaVoEktOYmqcrfV1G11 qapCFip0ADdu-n86tsHijzPAdDrq0ZzbhQFP2rU2oupM-D_MMivh4GMtS4Jlu_C42IR9zoAK23L1YfNATuRr9jhIc_mfKdgjk2XDJAHTkswfBpUtgAxiZM7p3qT4y QCK01j3U4Ec3Io\%3D\&tracking_referrer=www.bbc.co.uk (accessed on 27 November 2018) .

[42] Goodyear, P.; Goodyear, P. (). Educational design and networked learning: Patterns, pattern languages and design practice. Australasian Journal of Educational Technology, 2005, 21(1). Australasian Society for Computers in Learning in Tertiary Education. https://doi.org/10.14742/ajet.1344. Available online: https://ajet.org.au/index.php/AJET/article/view/1344 (accessed on 10 December, 2018).

[43] Wiener, Norbert, Cybernetics: Or Control and Communication in the Animal and the Machine. Cambridge, Massachusetts: MIT Press, 1948.

[44]H. R. Maturana, F. J. Varela, Autopoiesi e Cognizione, La realizzazione del vivente, Saggi Marsilio, Venice, 3rd edition; ISBN 88-317-4778-9.

[45] Nousala S. The Relevance of Scalability and Knowledge Transfer at Local and Global levels. Journal of Systemics, Cybernetics and Informatics (JSCI), 2013, $11(6), 75-81$. 
[46] Nousala S. Time and dynamic boundaries: the impact of action based learning. ISSS 2014 Conference, Learning Across Boundaries: Exploring the Variety of Systemic Theory and Practice, 58th Meeting of the International Society for the Systems Sciences, George Washington University, Washington DC, July 27 August 1, 2014.

[47]CSR Platform. Available online: https://mp.weixin.qq.com/s/pOS6d0UKjFPc_Hzqc2V2gQ (accessed on 5 January 2019).

[48] S. Mancuso, Plant Revolution, Le piante hanno già inventato il nostro futuro, ed. Giunti, Milano 2017, ISBN: 9788809857230.

[49]European Commission, Plants as robots or robots as plants, 6th October 2014, Last update: 27 February 2015. Available online: https://ec.europa.eu/digitalsingle-market/blog/plants-robots-or-robots-plants (Accessed on 15 November 2018).

(C) 2019 by the author(s); licensee International Technology and Science Publications (ITS), this work for open access publication is under the Creative Commons Attribution International License (CC BY 4.0). (http://creativecommons.org/licenses/by/4.0/) 